\title{
Advancements in hydrochemistry mapping: application to groundwater arsenic and iron concentrations in Varanasi, Uttar Pradesh, India
}

\section{Ricardo A. Olea ${ }^{1} \cdot$ N. Janardhana Raju ${ }^{2}$ Juan José Egozcue ${ }^{3} \cdot$ Vera Pawlowsky-Glahn $^{4}$ Shubhra Singh 5}

\begin{abstract}
The area east of Varanasi is one of the numerous places along the watershed of the Ganges River with groundwater concentrations of arsenic surpassing the maximum value of 10 parts per billion (ppb) recommended by the World Health Organization (WHO). Here we apply geostatistics and compositional data analysis for the mapping of arsenic and iron to help understanding the conditions leading to the occurrence of groundwater high in arsenic. The methodology allows for displaying concentrations of arsenic and iron as maps consistent with the limited information from 95 water wells across an area of approximately $210 \mathrm{~km}^{2}$; visualization of the uncertainty associated with the limited sampling; and summarizing the findings in the form of probability maps. Varanasi has been for thousands of years on the erosional side in a meander of the river that is free of arsenic values above $10 \mathrm{ppb}$. Maps reveal two anomalies of high arsenic concentrations on the depositional side of the valley, which has started to see urban development. The methodology for using geostatistics combined with compositional data analysis is completely general, so this study could be used as a prototype for hydrochemistry mapping in other areas.
\end{abstract}

Keywords Ganges River • geostatistics • stochastic simulation • compositional data analysis • isometric logratio transformation $\cdot$ balance

\footnotetext{
${ }^{1}$ U.S. Geological Survey, 12201 Sunrise Valley Drive, Mail Stop 956, Reston, VA 20192, USA; email: rolea@usgs.gov

${ }^{2}$ School of Environmental Sciences, Jawaharlal Nehru University, New Delhi 110067, India; email: rajunj7@gmail.com

${ }^{3}$ Department of Civil and Environmental Engineering, Polytechnical University of Catalonia, Barcelona, Spain; email: juan.jose.egozcue@upc.edu

${ }^{4}$ Department of Informatics, Applied Mathematics and Statistics, University of Girona, Spain; email: vera.pawlowsky@udg.edu

${ }^{5}$ Center for the Study of Science, Technology and Policy, Mayura Street, Bangalore 560094, India; email: shubh.bhu@gmail.com
} 


\section{Introduction}

Mapping of measurements taken at scattered locations across an area of interest is fundamental for analysis, modeling and characterization in hydrochemistry. The prevailing practice is by far the use of methods valid for the study of other attributes taking unrestricted real values. There are two major problems with those approaches: (a) geochemical data are often reported as concentrations, which are not real numbers in the standard sense, i.e. able to take any value between minus infinity and plus infinity, but constrained positive numbers denoting fractional contributions to a whole (Aitchison 2003), and (b) mapping requires the estimation of values complementing the information offered by the data and those calculations are often conducted applying methods, such as inverse distance weighting or spline interpolation, that do not take full advantage of the information inherent to the data (e.g., Isaaks and Srivastava 1989; Sha and Ahmad 2015; Meyzonnat et al. 2016).

Groundwater along the Ganges and Brahmaputra river basins commonly have levels of arsenic that are above the critical concentration of 10 parts per billion (ppb) established by the World Health Organization (WHO 2011). All in all, the problem exacerbates downstream, thus being more critical in Bangladesh, particularly at the delta (British Geological Survey 2001). Attention to the problem has come at a slower pace in India than in neighboring Bangladesh.

The objectives of this study are: (a) explain the fundamentals of mathematical modeling that today are necessary for a state-of-the art hydrochemistry mapping; (b) apply the methodology to some well measurements from Varanasi, thus illustrating the approach and offering clues for understanding the occurrence of high arsenic values in the groundwater of the area.

\section{Methodology}

\section{Geostatistics}

Geochemical mapping, such as one for arsenic concentrations, involves two basic steps: (a) interpolation and extrapolation of values at locations not considered in the surveying, and (b) display of the results. These two steps are common to multiple estimation problems in the earth sciences and engineering. Pooling of efforts has resulted in several related approaches. Here we borrow from geostatistics (e.g., Chilès and Delfiner 2012), stochastic simulation in particular (e.g., Caers 2011). Different from other methods, geostatistics has the advantage of considering the spatial continuity of the data and the capability of displaying the uncertainty associated with the modeling, which in classical geostatistics is accomplished through the use of the semivariogram (e.g., Webster and Oliver 2015).

Geostatistics, like statistics, heavily relies on the use of random variables for the modeling of attributes with a geographical variation, also called regionalized variables. Given an uncertain outcome, such as the casting of a die or the concentration of iron at a well not yet drilled, a 
random variable describes all possible outcomes and their relative likelihood of occurrence through a probability distribution (e.g., Olea 2009). In the simple case of the die, the outcomes are the integers between 1 and 6 , and, for a fair die, all probabilities are the same: 1/6. The random variable for the Fe concentration at a well not yet drilled is more complicated to come by and will require the rest of this section to explain it.

There are two families of mapping methods in geostatistics. Kriging is a generalization of least squares that provides single estimated values by minimizing the prediction error (e.g., Olea 2009). Stochastic simulation provides instead multiple maps that honor the data and the style of spatial fluctuation. In that regard, results from stochastic simulation are similar to the different responses that can be obtained by requesting to different experts to independently prepare a contour map based on values posted in a piece a paper.

From the always growing number of stochastic simulation methods, we use here sequential Gaussian simulation for its efficiency, versatility, easy application and wide acceptance (e.g., Pyrcz and Deutsch, 2014). The cornerstone of the method is the following simple multiplicative rule from probability theory:

$$
\operatorname{Prob}[A \cap B]=\operatorname{Prob}[A] \cdot \operatorname{Prob}[B \mid A],
$$

where $\operatorname{Prob}[A \cap B]$ is the probability that both events $A$ and $B$ take place simultaneously, $\operatorname{Prob}[A]$ is the probability that $A$ occurs and $\operatorname{Prob}[B \mid A]$ is the conditional probability of occurrence of $B$ when $A$ has been observed (e.g., Hogg et al. 2012).

A fundamental difference between classical statistics and geostatistics is the requirement of keeping track of data location, $\mathbf{s}_{i}$, which, in two-dimensions, is an abbreviated form to denote easting and northing. Differently from the notation in classical statistics, a random variable is denoted by $z\left(\mathbf{s}_{i}\right)$. Using the probability density function, $f(\cdot)$, and geostatistical notation to keep track of location, Eq. 1 can be rewritten as:

$$
f\left(z\left(\mathbf{s}_{1}\right), z\left(\mathbf{s}_{2}\right)\right)=f\left(z\left(\mathbf{s}_{1}\right)\right) \cdot f\left(z\left(\mathbf{s}_{2}\right) \mid z\left(\mathbf{s}_{1}\right)\right),
$$

expression that can be generalized to any number of locations, in our situation, nodes of a regular grid to prepare a pixel map. Sequential Gaussian simulation is a numerical implementation of Eq. 2 in which the interpolated values are obtained by drawing from normal distributions according to the following procedure (e.g., Emery 2004):

1. If the sample is not univariate normal, transform the data to normal scores (e.g., Pyrcz and Deutsch, 2014) and continue the modeling in terms of normal scores.

2. Find the semivariogram using standard modeling techniques (e.g., Olea 2006).

3. Schedule a random visitation of each of the nodes in the grid. 
4. Apply kriging considering all original data and, if this is not the first visited node, also all previously simulated values to obtain an estimated value $z^{*}\left(\mathbf{s}_{i}\right)$ and kriging standard error $\sigma^{*}\left(\mathbf{s}_{i}\right)$

5. Draw a value, $z_{G}\left(\mathbf{s}_{i}\right)$, from a normal distribution with parameters $z^{*}\left(\mathbf{s}_{i}\right)$ and $\sigma^{*}\left(\mathbf{s}_{i}\right)$; this is the simulated value at location $\mathbf{s}_{i}$.

6. Add $z_{G}\left(\mathbf{s}_{i}\right)$ to the expanded data set of the original measurements.

7. If this was not the last node to visit, go back to Step 4.

8. If a normal score transformation was necessary in Step 1, backtransform the results.

Each pixel map is an outcome called a realization. It is possible to explore the uncertainty space by changing the visitation schedule, thus generating different realizations. By replacing kriging by cokriging, the procedure can be generalized into a multivariate approach for the cosimulation of two or more attributes spatially correlated (Verly 1993). If a node coincides with a sampling location, by the kriging and cokriging exact interpolation property, $\sigma^{*}\left(\mathbf{s}_{i}\right)$ is zero. Consequently, sequential Gaussian simulation is also an exact interpolator reproducing all data without error or uncertainty. Each realization also reproduces the spatial correlation revealed by the observations. The public domain software SGeMS (Remy et al. 2009) was used for generating realizations.

As for the answer to the question at the beginning of this section, if for example 200 realizations for iron concentration are generated, the random variable $\mathrm{Fe}$ at location $\mathbf{s}_{i}$ is numerically approximated by the values at $\mathbf{s}_{i}$ in each one of the realizations, that is, a total of 200 values, in general all different and following a positively skewed distribution, such as a lognormal.

\section{Compositional data analysis}

Concentrations provide relative information among values of different components. This type of data is never negative and ordinarily, for every specimen, the complete set of parts adds to a constant, say 1,000,000 parts per million, or it can be represented this way. When zero concentration values are reported, the assumption that these values represent a non-null value below detection limit is commonly accepted (Palarea-Albaladejo and Martín-Fernández 2015). On the other hand, most statistical methods, such as sequential Gaussian simulation, have been formulated to work with real attributes theoretically ranging from $-\infty$ to $+\infty$ and honoring Euclidean geometry in real space (Pawlowsky-Glahn and Egozcue 2016). In addition, when modeled with standard methods, compositional data are known for presenting problems not shared by attributes varying in real space, such as spurious correlations and subcompositional incoherence (Aitchison 2003; Egozcue 2009; Greenacre 2011; Pawlowsky-Glahn et al. 2015c). 
The most efficient simultaneous solution to all these shortcomings has been changes in the data representation using various forms of logarithmic ratios (Aitchison 2003, Aitchison and Egozcue 2005), which are all related (Egozcue et al. 2003). An important feature is that these logratios can be used as coordinates representing the concentrations (Pawlowsky-Glahn and Egozcue 2001; Egozcue and Pawlowsky-Glahn 2006; Pawlowsky-Glahn et al. 2015c). Here we work with the isometric logratio transformation because it provides the most direct approach for geostatistics adequately modeling uncertainty. Geometrically, this transformation can be regarded as a projection of the compositional vectors onto an orthogonal basis. In the present study, we use a sequential binary partition for calculating the coordinates, in which case the coordinates receive the name of balances (Egozcue and Pawlowsky-Glahn 2005; Egozcue and Pawlowsky-Glahn 2011).

\section{The isometric logratio transformation}

Let us consider a sample of size $N$ at location $\mathbf{s}_{i} \in \Omega, i=1,2, \ldots, N$, across a spatial sampling domain and let us assume that there are $D$ chemical element parts associated with concentrations that can be treated as regionalized variables. Then at each location $\mathbf{s}_{i}$ there is a vector with $D$

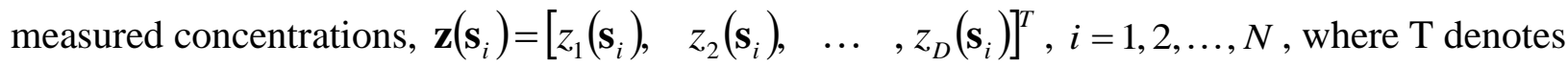
the transpose of a matrix, namely, the matrix that results from exchanging columns and rows. The $D-1$ balances $b_{j}\left(\mathbf{s}_{i}\right)$ are given by

$$
b_{j}\left(\mathbf{s}_{i}\right)=\sqrt{\frac{p_{j} \cdot n_{j}}{p_{j}+n_{j}}} \ln \frac{\left[\prod_{\theta_{j, k}=+1} z_{k}\left(\mathbf{s}_{i}\right)\right]^{1 / p_{j}}}{\left[\prod_{\theta_{j, k}=-1} z_{k}\left(\mathbf{s}_{i}\right)\right]^{1 / n_{j}}}, i=1,2, \ldots, N ; j=1,2, \ldots, D-1 ; k=1,2, \ldots, D,
$$

where $p_{j}, n_{j}$, and $k$ come from a partition matrix, $\boldsymbol{\Theta}$, separating the parts in a similar way as it is done with the data in cluster analysis. At each branching, $\theta_{j, k}=+1$ denotes the parts in one side of the partition and $\theta_{j, k}=-1$ in the other, with $\theta_{j, k}=0$ indicating that the concentration is not in any of the two branches. The number of +1 per row of the partition matrix $\boldsymbol{\Theta}$ is $p_{j}$ and $n_{j}$ is the number of -1 . For example, in a sample comprising four parts, the partition matrix plus the counts could be: 


$$
\begin{aligned}
& \begin{array}{llllll}
z_{1} & z_{2} & z_{3} & z_{4} & p_{j} & n_{j}
\end{array} \\
& \boldsymbol{\Theta}=\left[\begin{array}{cccc}
+1 & -1 & -1 & -1 \\
0 & +1 & -1 & -1 \\
0 & 0 & +1 & -1
\end{array}\right] \begin{array}{ll}
1 & 3 \\
1 & 2 \\
1 & 1
\end{array} \text {, }
\end{aligned}
$$

in which case the three balances are:

$$
\begin{aligned}
& b_{1}\left(\mathbf{s}_{i}\right)=\sqrt{\frac{1 \cdot 3}{1+3}} \ln \frac{z_{1}\left(\mathbf{s}_{i}\right)}{\left(z_{2}\left(\mathbf{s}_{i}\right) \cdot z_{3}\left(\mathbf{s}_{i}\right) \cdot z_{4}\left(\mathbf{s}_{i}\right)\right)^{1 / 3}}, \\
& b_{2}\left(\mathbf{s}_{i}\right)=\sqrt{\frac{1 \cdot 2}{1+2}} \ln \frac{z_{2}\left(\mathbf{s}_{i}\right)}{\left(z_{3}\left(\mathbf{s}_{i}\right) \cdot z_{4}\left(\mathbf{s}_{i}\right)\right)^{1 / 2}}, \\
& b_{3}\left(\mathbf{s}_{i}\right)=\sqrt{\frac{1 \cdot 1}{1+1}} \ln \frac{z_{3}\left(\mathbf{s}_{i}\right)}{z_{4}\left(\mathbf{s}_{i}\right)} .
\end{aligned}
$$

\section{Backtransforming estimated balances}

Balances may have interesting properties that sometimes are easy to interpret. Here, however, balances are used as auxiliary variables with the exclusive purpose of applying geostatistics; there is no intent or need to interpret them. Geostatistics uses the balances to generate estimated balances, $b_{j}^{*}\left(\mathbf{s}_{i}\right)$, which need to be backtransformed when the interest lies in displaying the results in the original part space. Similarly to the generation of balances, the backtransformation relies on a matrix to define terms. This is the contrast matrix, $\boldsymbol{\Psi}$, whose elements $\psi_{j, k}$ depend on the value of the elements $\theta_{j, k}$ of the partition matrix $\boldsymbol{\Theta}$.

$$
\psi_{j, k}=\left\{\begin{array}{c}
0, \text { if } \theta_{j, k}=0, \\
\sqrt{\frac{n_{j}}{p_{j} \cdot\left(p_{j}+n_{j}\right)}}, \text { if } \theta_{j, k}=+1, \\
-\sqrt{\frac{p_{j}}{n_{j} \cdot\left(p_{j}+n_{j}\right)}}, \text { if } \theta_{j, k}=-1,
\end{array}\right.
$$

with $j=1,2, \ldots, D-1 ; k=1,2, \ldots, D$. The backtransformed values, $\mathbf{z}^{*}\left(\mathbf{s}_{i}\right)$, are given by

$$
\mathbf{z}^{*}\left(\mathbf{s}_{i}\right)=c^{*}\left(\mathbf{s}_{i}\right) \cdot \exp \left(\boldsymbol{\Psi}^{\mathrm{T}} \cdot \mathbf{b}^{*}\left(\mathbf{s}_{i}\right)\right), i=1,2, \ldots, N,
$$

where $\mathbf{b}^{*}\left(\mathbf{s}_{i}\right)$ is the vector of estimated balances: $\mathbf{b}^{*}\left(\mathbf{s}_{i}\right)=\left[\begin{array}{llll}b_{1}^{*}\left(\mathbf{s}_{i}\right), & b_{2}^{*}\left(\mathbf{s}_{i}\right), \quad \ldots \quad, b_{D-1}^{*}\left(\mathbf{s}_{i}\right)\end{array}\right]^{T}$ and the estimated scaling factor $c^{*}\left(\mathbf{s}_{i}\right)$ is 


$$
c^{*}\left(\mathbf{s}_{i}\right)=\frac{\kappa}{\sum_{j=1}^{D} \exp \left(\left[\boldsymbol{\Psi}^{\mathrm{T}} \cdot \mathbf{b}^{*}\left(\mathbf{s}_{i}\right)\right]_{j}\right)},
$$

where the bracket []$_{j}$ denotes the $j$ th component of the vector. Eq. 7 presumes that the sum of all parts adds to a constant $\kappa$ for any $\mathbf{s}_{i}$ (Pawlowsky-Glahn et al. 2015a). If not all parts in the system have been measured, then $z_{D}\left(\mathbf{s}_{i}\right)=\kappa-\sum_{j=1}^{D-1} z_{j}\left(\mathbf{s}_{i}\right)$ becomes the collective contribution of all parts without measurements, with $D-1$ being the number of parts with measurements. If all of the parts are not supposed to add to a constant, or there is interest in reducing the dimensionality of the modeling by not calculating all balances while still using all information available, or both, one possibility is to use

$$
c^{*}\left(\mathbf{s}_{i}\right)=\frac{\left(\sum_{j=1}^{m} z_{j}\left(\mathbf{s}_{i}\right)\right)^{*}}{\sum_{j=1}^{m} \exp \left(\left[\left(\Psi^{\mathrm{T}} \cdot \mathbf{b}^{*}\left(\mathbf{s}_{i}\right)\right)\right]_{j}\right)},
$$

where the summation is over all variables of interest, with $m$ denoting their total number and the asterisk indicating an estimate (Pawlowsky-Glahn et al. 2015b). By Eq. 4 and 5, the contrast matrix for the illustrative example is:

$$
\boldsymbol{\Psi}=\left[\begin{array}{cccc}
\sqrt{\frac{3}{1 \cdot(1+3)}} & -\sqrt{\frac{1}{3 \cdot(1+3)}} & -\sqrt{\frac{1}{3 \cdot(1+3)}} & -\sqrt{\frac{1}{3 \cdot(1+3)}} \\
0 & \sqrt{\frac{2}{1 \cdot(1+2)}} & -\sqrt{\frac{1}{2 \cdot(1+2)}} & -\sqrt{\frac{1}{2 \cdot(1+2)}} \\
0 & 0 & \sqrt{\frac{1}{1 \cdot(1+1)}} & -\sqrt{\frac{1}{1 \cdot(1+1)}}
\end{array}\right] .
$$

Therefore, by Eq. 6, the backtransformed parts are 


$$
\mathbf{z}^{*}\left(\mathbf{s}_{i}\right)=c^{*}\left(\mathbf{s}_{i}\right) \cdot \exp \left(\left[\begin{array}{ccc}
{\left[\begin{array}{ccc}
\sqrt{\frac{3}{1 \cdot(1+3)}} & 0 & 0 \\
-\sqrt{\frac{1}{3 \cdot(1+3)}} & \sqrt{\frac{2}{1 \cdot(1+2)}} & 0 \\
-\sqrt{\frac{1}{3 \cdot(1+3)}} & -\sqrt{\frac{1}{2 \cdot(1+2)}} & \sqrt{\frac{1}{1 \cdot(1+1)}} \\
-\sqrt{\frac{1}{3 \cdot(1+3)}} & -\sqrt{\frac{1}{2 \cdot(1+2)}} & -\sqrt{\frac{1}{1 \cdot(1+1)}}
\end{array}\right] \cdot\left[b_{2}^{*}\left(\mathbf{s}_{i}\right)\right.} \\
b_{3}^{*}\left(\mathbf{s}_{i}\right)
\end{array}\right]\right) .
$$

The final solution is obtained applying Eq. 7 or 8, whichever applies.

The transformation and backtransformation processes have the following properties among others: (a) the results of the modeling do not depend on the selection of the partition matrix (Pawlowsky-Glahn et al. 2015c), and (b) it is possible to define and calculate only a few of all possible balances, flexibility that will be applied and illustrated in the case study; choosing only few balances is equivalent to perform an orthogonal projection on a subspace generated for the chosen balances, thus providing a dimension reduction (Egozcue and Pawlowsky-Glahn 2005; Pawlowsky-Glahn et al. 2015b). All compositional data modeling was done using software coded by the senior author.

\section{Case study}

The Ganges River is the major stream in Varanasi, draining the west side of the city and flowing from south to north (Fig. 1), eventually reaching the Bengal Bay roughly to the southeast. The city of Varanasi is in the middle part of the Indo-Gangetic plain at an average height of $76.2 \mathrm{~m}$ above the mean sea level with even topography which lies between the peninsular India and the Siwalik range which represents alluvial deposits filling the Himalayan foreland. 


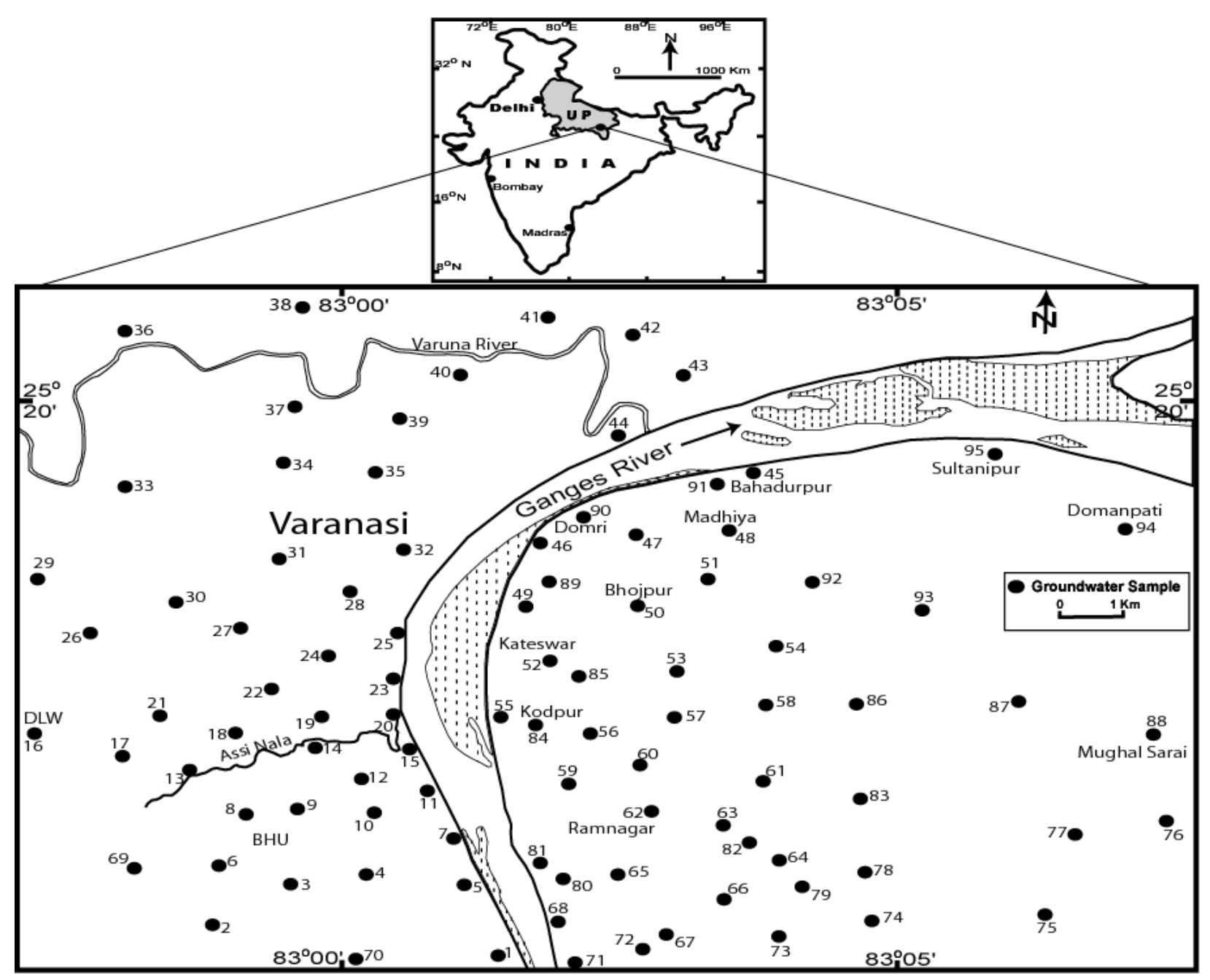

Fig. 1 Location map, with numbers denoting the location identifiers in Table A1. The textured areas inside the river denote sand banks.

\section{Geology}

The majority of the sediments deposited in the foreland basin have their source in the Himalayas, where sediment production is attributed to the episodic tectonic activity and climate variability (Srivastava et al. 2003; Singh et al. 2007). According to Tandon et al. (2006), the Ganges plain lies within one of the world's most active tectonic and southwest monsoon dominated regions in the world. Climatic and tectonic changes with time have caused the development of various geomorphic surfaces and features, which are regionally persistent in the plain (Singh 2004).

The availability of groundwater in the Ganges alluvial zones is controlled by the thickness of sand and clay zones. The alternating sand and clay layers have created a multi-tier aquifer system in the Varanasi area (Shukla and Raju 2008). The top $25 \mathrm{~m}$ of the alluvial deposits are dominated by clay, silt, and sandy clay with thin lenses of sands. In the study area in particular, the groundwater is under phreatic condition at least up to $100 \mathrm{~m}$ of depth. All water samples were 
taken from depths shallower than $100 \mathrm{~m}$. Depth of water level varies between 5 and $29 \mathrm{~m}$ below ground level. The water level shows lowering trends in some parts of the study area because of fast urbanization and intensive pumping for domestic and irrigation use. Groundwater is extracted through dug wells, hand tube wells and deep bore wells. Dug wells and shallow tube wells (hand pumps) mainly tap the unconfined aquifers. General depth of hand tube wells and deep bore wells ranges 60-70 $\mathrm{m}$ and 80-250 $\mathrm{m}$ below ground level, respectively, and at the deeper levels aquifer occurs in semi-confined to confined conditions.

Arsenic contaminated aquifers are pervasive throughout the entire Ganges River basin (Chakraborti et al. 2003; Srivastava et al. 2003; Acharyya 2005; Tandon et al. 2006; Singh et al. 2007; Chauhan et al. 2009; Kumar et al. 2010; Shah 2010; Raju 2012; Srivastava and Sharma 2013; Saha and Shukla 2013; Chandana et al. 2015; Singh et al. 2016; Kumar et al. 2016). Geomorphological controls, such as the meandering pattern of the Ganges and Brahmaputra River, is responsible for the localized depositions of arsenic rich sediments along the course of the river. Consequently, groundwater arsenic contamination is not uniformly found in the Ganges plain, but is present in pockets along different states of India (Charkraborti et al. 2003). According to McArthur et al. (2001), high concentrations of arsenic are restricted to Holocene sediments rich in organic matter resulting in a reducing environment. High concentrations of iron also seem to play a role in releasing arsenic from minerals in the sediments. Arsenic is adsorbed by iron oxides, which form a part of fine grained sediments. These sediments are rapidly reduced because the rich organic matter consumes oxygen. Release of arsenic into the groundwater takes place after a series of geochemical reactions.

\section{Laboratory analysis}

A total of 95 groundwater samples from dug wells, hand pumps, and deep bore wells (Fig. 1) in the study area were collected during May 2007 (samples 1-68) and in May 2012 (samples 69-95) and analyzed to understand chemical variations in groundwater quality. The results are listed in the Appendix. Concentrations are reported in $\mathrm{mg} / \mathrm{L}$, that is, in units of mass per volume, which is only approximately equal but not exactly the same as the dimensionless part per million (ppm) given that the mass of one liter is not exactly equal to one kilogram because the groundwater density varies with fluctuations in ion concentrations. The arsenic and iron concentrations are reported in $\mu \mathrm{g} / \mathrm{L}$ to have larger values.

Samples collected were filtered using $0.45 \mu \mathrm{m}$ pore size membrane and stored in polyethylene bottles which are initially washed with $10 \% \mathrm{HNO}_{3}$ and rinsed thoroughly three times with distilled water. A duplicate set of samples was collected and acidified to $\mathrm{pH}<2$ by adding ultra-pure concentrated $\mathrm{HNO}_{3}$ for heavy metal measurements. Physico-chemical characteristics of groundwater samples were determined using standard analytical methods (Rice et al. 2012). Physical parameters like $\mathrm{pH}$ and electrical conductivity were measured with portable ion meters (Elico Model). Total hardness and calcium were estimated by EDTA titrimetric 
method, and magnesium estimated by the difference of the hardness and calcium. Total alkalinity, carbonate and bicarbonate as well as chloride were estimated by titrimetric method. Sodium and potassium were estimated by flame photometer (Elico Model CL-378). Sulfate estimations were done by the gravimetric method. Nitrate and iron were analyzed by the UVspectrophotometer (Lab India Model UV 3000). Fluoride was measured using an ion analyzer (Orion Model 4 star) with an ion selective electrode. Total arsenic in groundwater was determined by flow-injection-hydride generation atomic absorption spectrometry (FI-HG-AAS) (Perkin Elmer). The accuracy of the analytical method using FI-HG-AAS was verified for arsenic by analyzing Standard Reference Materials from Environmental Monitoring and Support Laboratory of the U. S. Environmental Protection Agency, Cincinnati, OH, USA. The analytical precision for the measurement was determined by calculating the ionic balance error, which is generally found to be within $\pm 5 \%$. Ion speciation in groundwater was calculated using computer code WATEQ4F program (Ball and Nordstrom 1992). In this publication, the interest was restricted to the mapping of the concentration of iron and arsenic, considering the effect of the rest of the ions but disregarding the rest of the non-compositional measurements, such as $\mathrm{pH}$ and electrical conductivity.

\section{The partition matrix}

As explained above, the data need to be pre-processed before applying geostatistics and the results in terms of the pre-processed balances need to be backtransformed. Here, to facilitate the understanding, we illustrate those steps numerically just for one location before going into the massive generation of maps covering the entire area of interest. The very first step in the preprocessing is the preparation of the partition matrix, which remain the same during the entire study.

There are 11 measured parts in this case (Table A1): Fe $\left(z_{1}\left(\mathbf{s}_{i}\right)\right)$, As $\left(z_{2}\left(\mathbf{s}_{i}\right)\right), \mathrm{Ca}\left(z_{3}\left(\mathbf{s}_{i}\right)\right), \mathrm{Mg}$

$\left(z_{4}\left(\mathbf{s}_{i}\right)\right), \mathrm{Na}\left(z_{5}\left(\mathbf{s}_{i}\right)\right), \mathrm{K}\left(z_{6}\left(\mathbf{s}_{i}\right)\right), \mathrm{HCO}_{3}\left(z_{7}\left(\mathbf{s}_{i}\right)\right), \mathrm{SO}_{4}\left(z_{8}\left(\mathbf{s}_{i}\right)\right), \mathrm{Cl}\left(z_{9}\left(\mathbf{s}_{i}\right)\right), \mathrm{NO}_{3}\left(z_{10}\left(\mathbf{s}_{i}\right)\right)$ and F $\left(z_{11}\left(\mathbf{s}_{i}\right)\right)$. As the interest is restricted to the mapping of the first two parts, Fe and As, it is not necessary to define the entire partition matrix, which we decided to be: 


$$
\boldsymbol{\Theta}=\left[\begin{array}{ccccccccccc}
-1 & -1 & +1 & +1 & +1 & +1 & +1 & +1 & +1 & +1 & +1 \\
+1 & -1 & 0 & 0 & 0 & 0 & 0 & 0 & 0 & 0 & 0 \\
0 & 0 & . & . & . & . & . & . & . & . & . \\
0 & 0 & . & . & . & . & . & . & . & . & . \\
0 & 0 & . & . & . & . & . & . & . & . & . \\
0 & 0 & . & . & . & . & . & . & . & . & . \\
0 & 0 & . & . & . & . & . & . & . & . & . \\
0 & 0 & . & . & . & . & . & . & . & . & . \\
0 & 0 & . & . & . & . & . & . & . & . & . \\
0 & 0 & . & . & . & . & . & . & . & . & .
\end{array}\right],
$$

where the dots denote unspecified values. Consequently, according to Eq. 3, the first two balances are:

$$
\begin{gathered}
b_{1}\left(\mathbf{s}_{i}\right)=\sqrt{\frac{9 \cdot 2}{9+2}} \ln \frac{\left(z_{3}\left(\mathbf{s}_{i}\right) \cdot z_{4}\left(\mathbf{s}_{i}\right) \cdot z_{5}\left(\mathbf{s}_{i}\right) \cdot z_{6}\left(\mathbf{s}_{i}\right) \cdot z_{7}\left(\mathbf{s}_{i}\right) \cdot z_{8}\left(\mathbf{s}_{i}\right) \cdot z_{9}\left(\mathbf{s}_{i}\right) \cdot z_{10}\left(\mathbf{s}_{i}\right) \cdot z_{11}\left(\mathbf{s}_{i}\right)\right)^{1 / 9}}{\left(z_{1}\left(\mathbf{s}_{i}\right) \cdot z_{2}\left(\mathbf{s}_{i}\right)\right)^{1 / 2}}, \\
b_{2}\left(\mathbf{s}_{i}\right)=\sqrt{\frac{1 \cdot 1}{1+1}} \ln \frac{z_{1}\left(\mathbf{s}_{i}\right)}{z_{2}\left(\mathbf{s}_{i}\right)} .
\end{gathered}
$$

Note that, because of the form of the first balance, although we are not interested in mapping ions other than $\mathrm{Fe}$ and $\mathrm{As}$, the transformations still use information from the additional nine ions, thus the logratios depend on all 11 ions. For the first well (Table A1), the concentrations are $\mathrm{Fe}=0.285 \mathrm{mg} / \mathrm{L}, \mathrm{As}=0.0023 \mathrm{mg} / \mathrm{L}$ and for the other ions $62,31.3,13.9,3.6,334,10,35,7.3$, $0.89 \mathrm{mg} / \mathrm{L}$. Hence

$$
\begin{gathered}
b_{1}\left(\mathbf{s}_{1}\right)=\sqrt{\frac{9 \cdot 2}{9+2}} \ln \frac{(62 \cdot 31.3 \cdot 13.9 \cdot 3.6 \cdot 334 \cdot 10 \cdot 35 \cdot 7.3 \cdot 0.89)^{1 / 9}}{(0.285 \cdot 0.0023)^{1 / 2}}=8.24511, \\
b_{2}\left(\mathbf{s}_{1}\right)=\sqrt{\frac{1 \cdot 1}{1+1}} \ln \frac{0.285}{0.0023}=3.40796 .
\end{gathered}
$$

\section{The contrast matrix}

For the case of the partition matrix in Eq. 9, the 11 by 10 contrast matrix is 


$$
\boldsymbol{\Psi}=\left[\begin{array}{ccccc}
-\sqrt{\frac{9}{2 \cdot(2+9)}} & -\sqrt{\frac{9}{2 \cdot(2+9)}} & \sqrt{\frac{2}{9 \cdot(2+9)}} & \cdots & \sqrt{\frac{2}{9 \cdot(2+9)}} \\
\sqrt{\frac{1}{1 \cdot(1+1)}} & -\sqrt{\frac{1}{1 \cdot(1+1)}} & 0 & \cdots & 0 \\
0 & 0 & . & \ldots & . \\
\ldots & \ldots & \ldots & \ddots & \ldots \\
0 & 0 & . & \cdots & .
\end{array}\right] .
$$

For estimated balances $\mathbf{b}^{*}\left(\mathbf{s}_{i}\right)$, the backtransformed, estimated parts are

$$
\mathbf{z}^{*}\left(\mathbf{s}_{i}\right)=c^{*}\left(\mathbf{s}_{i}\right) \cdot \exp \left(\left[\begin{array}{ccccc}
-\sqrt{\frac{9}{2 \cdot(2+9)}} & \sqrt{\frac{1}{1 \cdot(1+1)}} & 0 & \cdots & 0 \\
-\sqrt{\frac{9}{2 \cdot(2+9)}} & -\sqrt{\frac{1}{1 \cdot(1+1)}} & 0 & \cdots & 0 \\
\sqrt{\frac{2}{9 \cdot(2+9)}} & 0 & \cdot & \cdots & \cdot \\
\sqrt{\frac{\ldots}{9 \cdot(2+9)}} & 0 & \cdot & \ddots & \cdot
\end{array}\right] \cdot\left[\begin{array}{c}
b_{1}^{*}\left(\mathbf{s}_{i}\right) \\
\cdot \\
\vdots \\
\cdot
\end{array}\right]\right) .
$$

Considering that we are interested only in $z_{1}^{*}\left(\mathbf{s}_{i}\right)$ and $z_{2}^{*}\left(\mathbf{s}_{i}\right)$, we set to 0 all estimated balances from $b_{3}^{*}\left(\mathbf{s}_{i}\right)$ to $b_{11}^{*}\left(\mathbf{s}_{i}\right)$, which is equivalent to projecting the composition into a two dimensional subspace, thus ignoring 9 coordinate-balances:

$$
\begin{aligned}
& z_{1}^{*}\left(\mathbf{s}_{1}\right)=c\left(\mathbf{s}_{i}\right) \cdot \exp \left(-\sqrt{\frac{9}{2 \cdot(2+9)}} \cdot b_{1}^{*}\left(\mathbf{s}_{i}\right)+\sqrt{\frac{1}{1 \cdot(1+1)}} \cdot b_{2}^{*}\left(\mathbf{s}_{i}\right)\right) \\
& z_{2}^{*}\left(\mathbf{s}_{1}\right)=c\left(\mathbf{s}_{i}\right) \cdot \exp \left(-\sqrt{\frac{9}{2 \cdot(2+9)}} \cdot b_{1}^{*}\left(\mathbf{s}_{i}\right)-\sqrt{\frac{1}{1 \cdot(1+1)}} \cdot b_{2}^{*}\left(\mathbf{s}_{i}\right)\right)
\end{aligned}
$$

Given that, in addition, the sum of all parts in this case does not add up to a constant value, it is necessary to use Eq. 8 to recover the original units in $\mathrm{mg} / \mathrm{L}$. Because the interest is in mapping Fe and As, Eq. 8 turns into

$$
c^{*}\left(\mathbf{s}_{i}\right)=\frac{\left(z_{1}\left(\mathbf{s}_{1}\right)+z_{2}\left(\mathbf{s}_{1}\right)\right)^{*}}{\exp \left(\left[\boldsymbol{\Psi}^{\mathrm{T}} \cdot \mathbf{b}^{*}\left(\mathbf{s}_{i}\right)\right]_{1}\right)+\exp \left(\left[\boldsymbol{\Psi}^{\mathrm{T}} \cdot \mathbf{b}^{*}\left(\mathbf{s}_{i}\right)\right]_{2}\right)},
$$

where, again, the asterisks denote estimated values. Let us assume that $b_{1}^{*}\left(\mathbf{s}_{1}\right)=8.24511$, $b_{2}^{*}\left(\mathbf{s}_{1}\right)=3.40796$ and $\left(z_{1}\left(\mathbf{s}_{1}\right)+z_{2}\left(\mathbf{s}_{1}\right)\right)^{*}=0.2873$. By Eq. 16 and 17: 


$$
\begin{aligned}
& z_{1}^{*}\left(\mathbf{s}_{1}\right)=c^{*}\left(\mathbf{s}_{i}\right) \cdot 0.057022 \\
& z_{2}^{*}\left(\mathbf{s}_{1}\right)=c^{*}\left(\mathbf{s}_{i}\right) \cdot 0.00046 .
\end{aligned}
$$

Scaling by Eq. 18

$$
\begin{aligned}
& z_{1}^{*}\left(\mathbf{s}_{1}\right)=\frac{0.2873}{0.057022+0.00046} \cdot 0.057022=0.285 \\
& z_{2}^{*}\left(\mathbf{s}_{1}\right)=\frac{0.2873}{0.057022+0.00046} \cdot 0.00046=0.0023
\end{aligned}
$$

we obtain the estimated values in $\mathrm{mg} / \mathrm{L}$ of $\mathrm{Fe}$ and $\mathrm{As}$, respectively. Note that these two concentrations are exactly the same values used to calculate the balances. This result is obtained because there is always a bijection between the original space of the parts and that of the logratios.

\section{Preparation of the maps}

Fig. 2 displays the data for the elements of main interest: iron and arsenic. It can be seen that the distributions are right skewed. Note that the summary statistics in Fig. 2 include a "compositional mean". One of the many peculiarities of compositional data is that the straight calculation of most moments from the data is invalid, but is valid for all quantiles. For most moments, the coherent values are those calculated based on the logratio transformations and then backtransformed. Unfortunately, the operation is not always possible, the variance being one case. For example, from Fig. 3, the mean values for the logratio transformations are (7.957, $3.517,-2.229)$. The backtransformed values using Equations (18), (19) and (20), 675.6 and 4.7 $\mu \mathrm{g} / \mathrm{L}$, here called compositional mean, are the values for the mean concentration of Fe and As, not those calculated directly as arithmetic means of the observations, which are $(1000.5,9.3)$. The geometric mean is one of the few moments that can be calculated directly from the data, thus its popularity among compositional analysts, but not necessarily among earth scientist.

Consequently, we list both. 
(a)

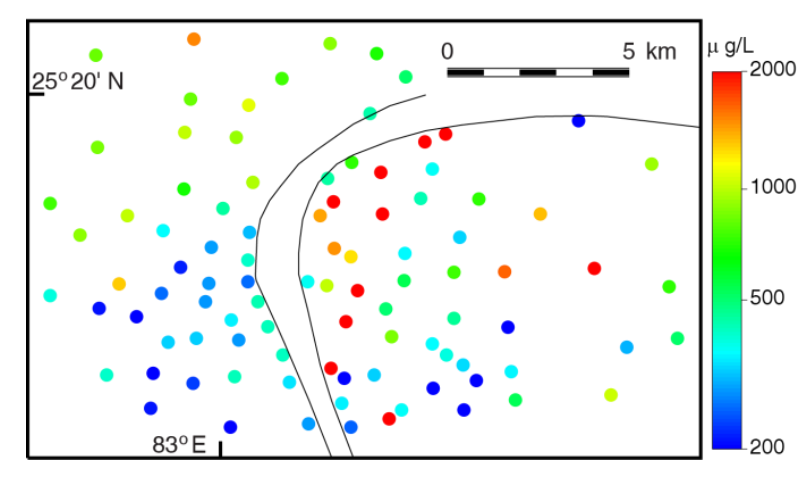

(c)

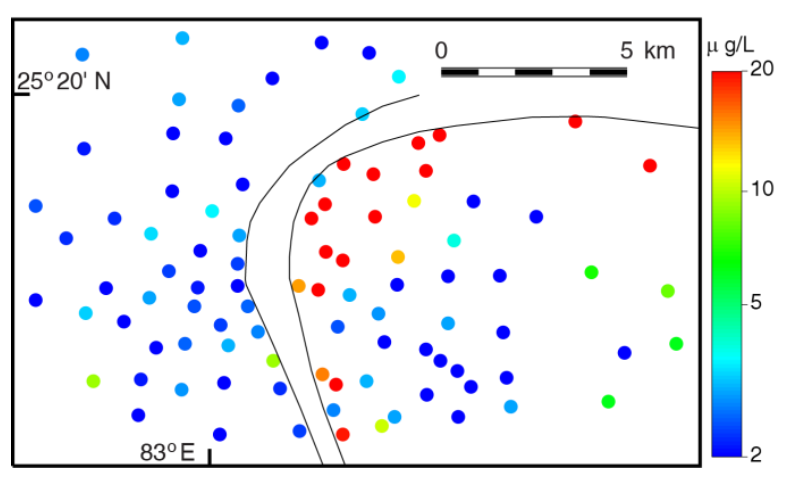

(b)

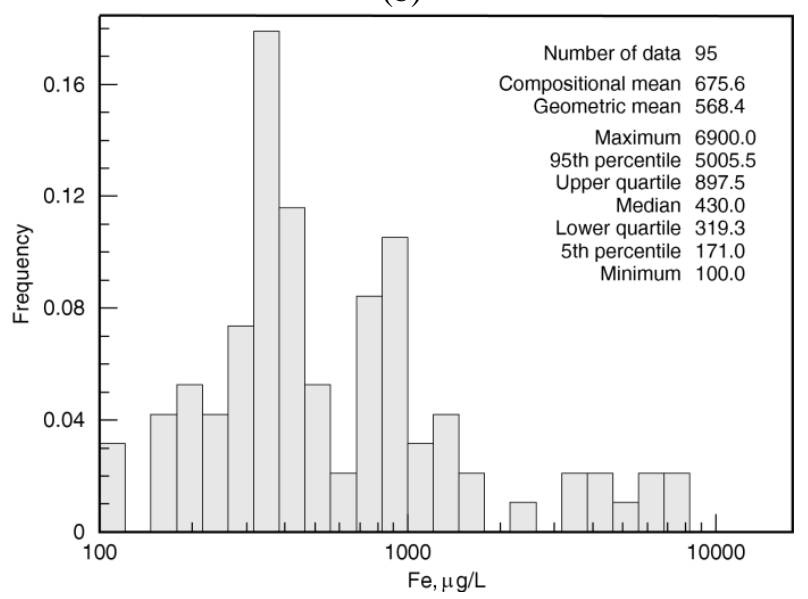

(d)

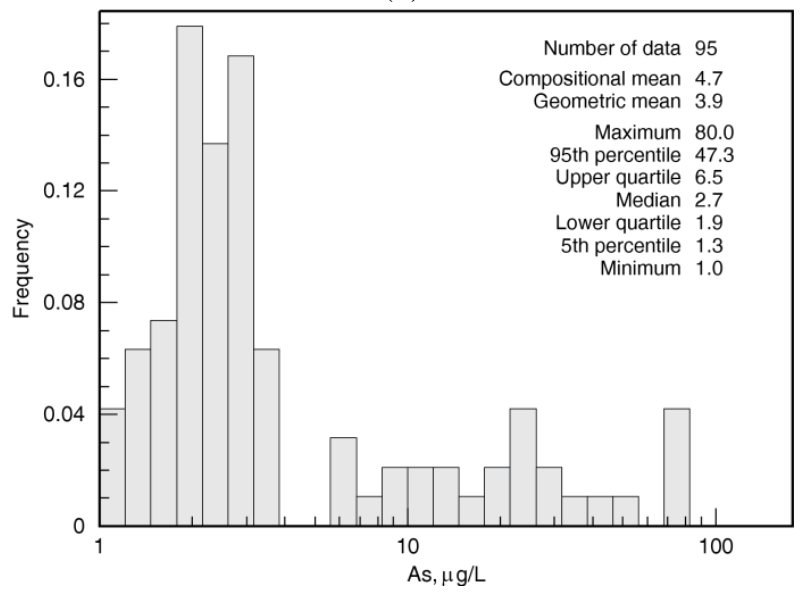

Fig. 2 Display of well data for iron ( $a$ and b) and arsenic (c and d). Posting of values is in logarithmic scale, with the curves denoting the margins of the Ganges River.

Because we will use Eq. 18 for the backtransformation of the balances, we need to prepare an estimate of the sum of iron plus arsenic, which also requires a logratio transformation, for which we have selected the following pseudologit:

$$
\operatorname{plogit}\left(\mathbf{s}_{i}\right)=\ln \frac{z_{1}\left(\mathbf{s}_{1}\right)+z_{2}\left(\mathbf{s}_{1}\right)}{p-\left(z_{1}\left(\mathbf{s}_{1}\right)+z_{2}\left(\mathbf{s}_{1}\right)\right)} .
$$

In a logit, parameter $p$ is the maximum possible value for the variable in the denominator. Here instead, we have taken $p=7.0$, which is a value close but larger than the maximum value of $6.915 \mathrm{mg} / \mathrm{L}$ in the sample (well 81, Table A1). Fig. 3 shows the two balances and the pseudologit. 
(a)

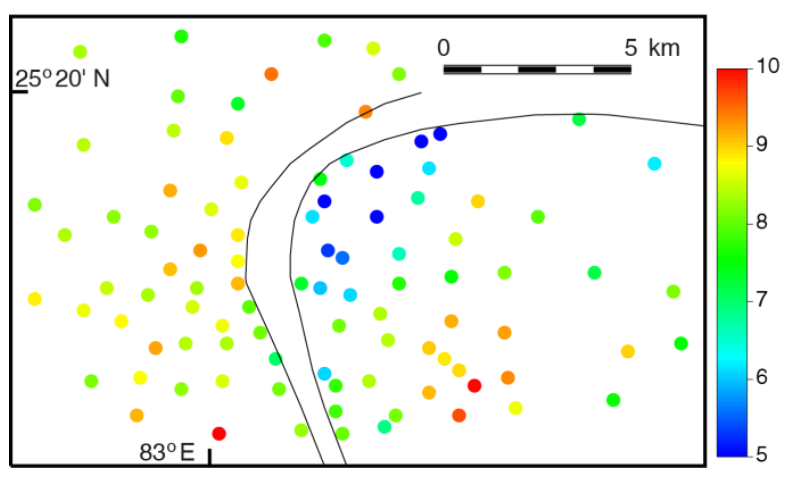

(c)

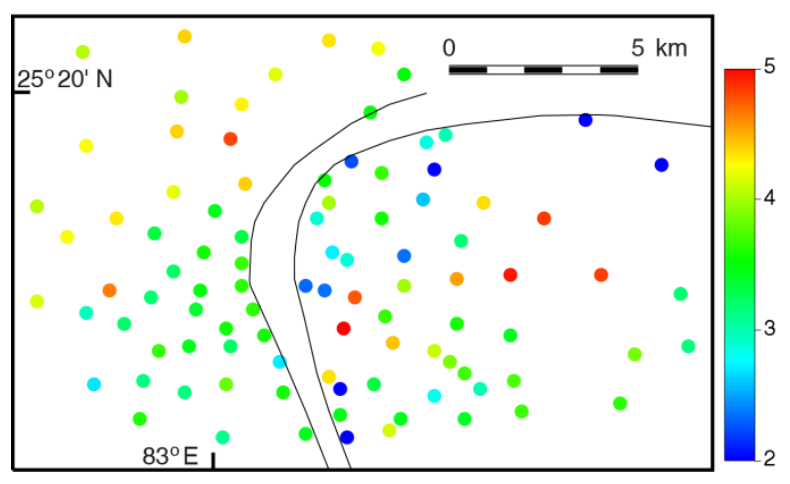

(e)

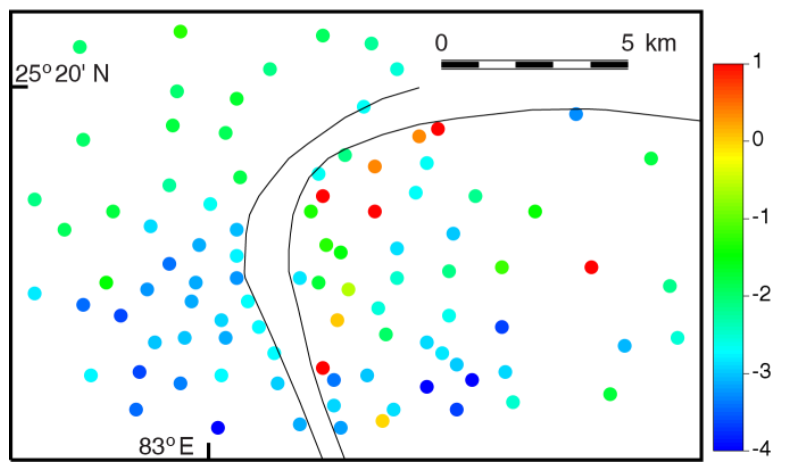

(b)

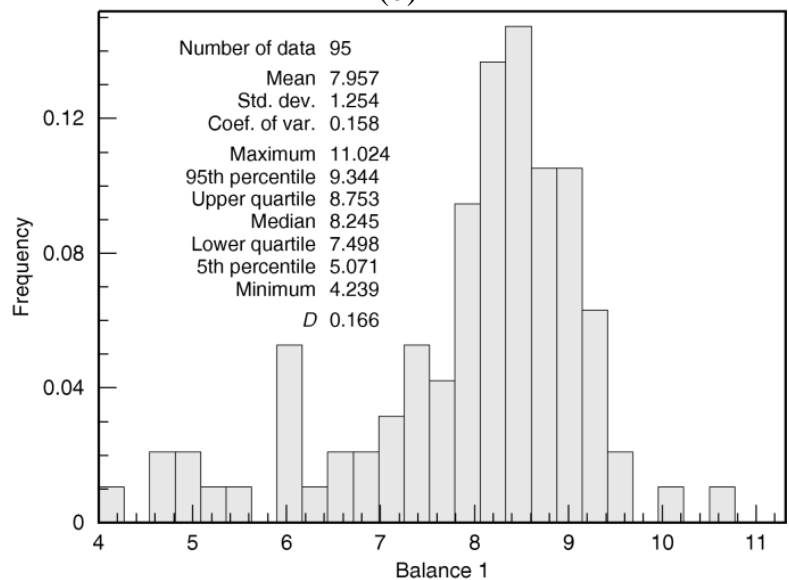

(d)

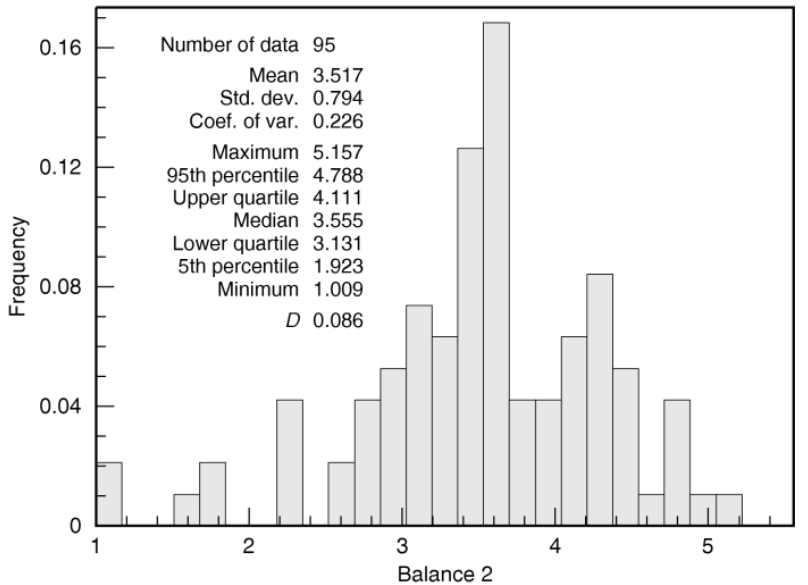

(f)

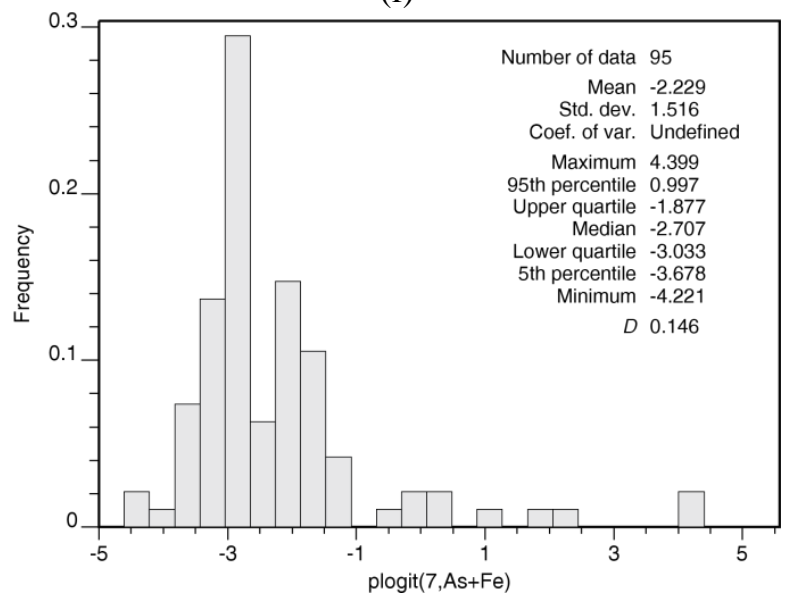

Fig. 3 The logratio transformed data for balance 1 (Eq. 10) (a and b); balance 2 (Eq.11) (c and d) and pseudologit for the sum of iron and arsenic (Eq. 23) (e and f). The curves in the maps denote the margins of the Ganges River. $D$ is the maximum discrepancy between the displayed distribution and a normal distribution with the same mean and variance. 
Calculation of the logratio transformations marks the end of the data preparation necessary for the adequate application of geostatistics.

The interest in our case is in sequential Gaussian simulation, which, as we have seen, requires not only that the data can vary from $-\infty$ to $+\infty$, but also that the univariate distributions be normal, which is hardly the case here, perhaps with the sole exception of balance 2 in Fig. 3. Hence, normal score transformations are in order. Note that, because normal scores will be used in the modeling instead of the pseudologit, given that both types of transformations are monotonous, the normal score transformation is the same regardless of the value selected for parameter $p$.

The next step according to the sequential Gaussian simulation procedure in the Geostatistics Section is the structural analysis, which did not find any significant anisotropies. Fig. 4 and Table 1 show that all cross-semivariograms follow pure nugget effect models, except for the cross-semivariogram between the normal scores of balance 1 and of the pseudologit for the sum of the concentrations of arsenic and iron. Hence, balance 2 should be modeled applying sequential Gaussian simulation because their normal scores are not spatially correlated to the normal scores of the other two logratios. The mapping of the other two variables will benefit with the use of sequential Gaussian cosimulation, although marginally because the data are all collocated. 

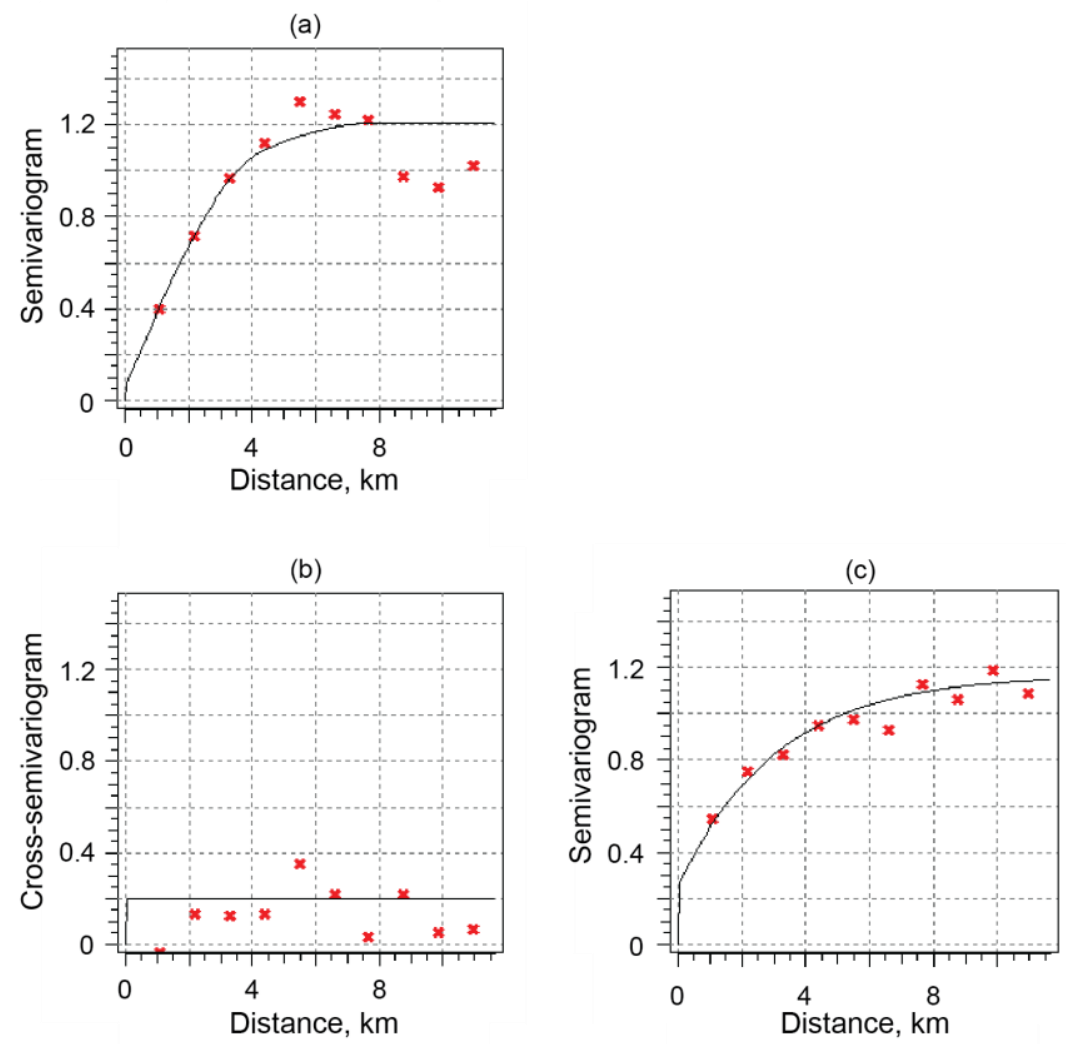

(d)

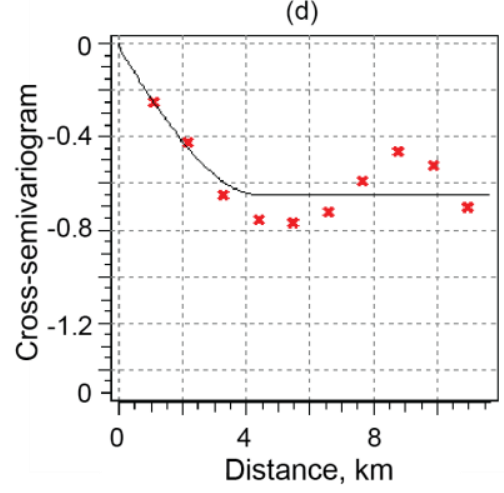

(e)
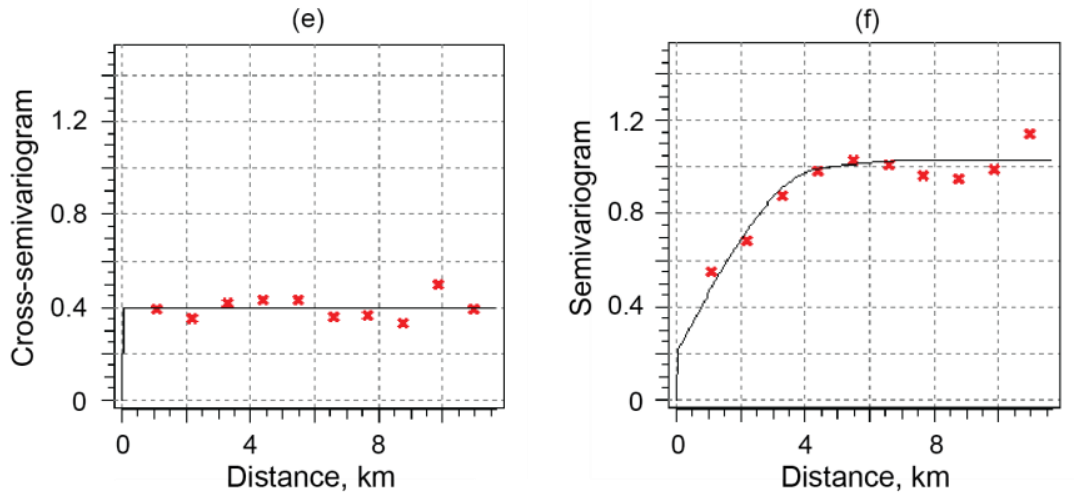

Fig.4 Structural analysis of normal scores of the logratio data in Fig. 3, with red crosses denoting empirical values and curves the best fitting models in Table 1: (a) semivariogram for balance 1; (b) cross-semivariogram between balance 1 and balance 2; (c) semivariogram for balance 2; (d) cross-semivariogram between balance 1 and pseudologit of the sum; (e) cross-semivariogram between balance 2 and pseudologit of the sum; and (f) semivariogram for the pseudologit of the sum. 
Table 1 Parameters for the models best fitting to the empirical values in Fig. 4. S-N denotes sill minus nugget, $\mathrm{R}$ the range, the root bal denotes balance, exponent. is the abbreviation for exponential, and plogit for pseudologit.

\begin{tabular}{|l|c|l|c|c|c|c|c|}
\hline Variable(s) & Nugget & Type & $\mathrm{S}-\mathrm{N}$ & $\mathrm{R}, \mathrm{km}$ & Type & $\mathrm{S}-\mathrm{N}$ & $\mathrm{R}, \mathrm{km}$ \\
\hline bal1 & 0.06 & spherical & 0.7 & 4.4 & spherical & 0.45 & 8.0 \\
\hline bal1-bal2 & 0.2 & & & & & & \\
\hline bal1-plogit & -0.02 & spherical & -0.63 & 4.4 & & & \\
\hline bal2 & 0.25 & exponent. & 0.92 & 9.2 & & & \\
\hline bal2-plogit & 0.4 & & & & & & \\
\hline plogit & 0.2 & spherical & 0.68 & 4.4 & spherical & 0.15 & 8.0 \\
\hline
\end{tabular}

In this study, it is sufficient to limit the number of realizations to 100 per variable to properly cover the uncertainty space, that is, a total of 300 realizations. Space restrictions do not allow display of all 300 realizations. Under the circumstances, we have arbitrarily limited the rendition to the first realization for each one of the logratios, which appear in Fig. 5. The mapping is completed by backtransforming each one of the 100 triplets of realizations. 
(a)

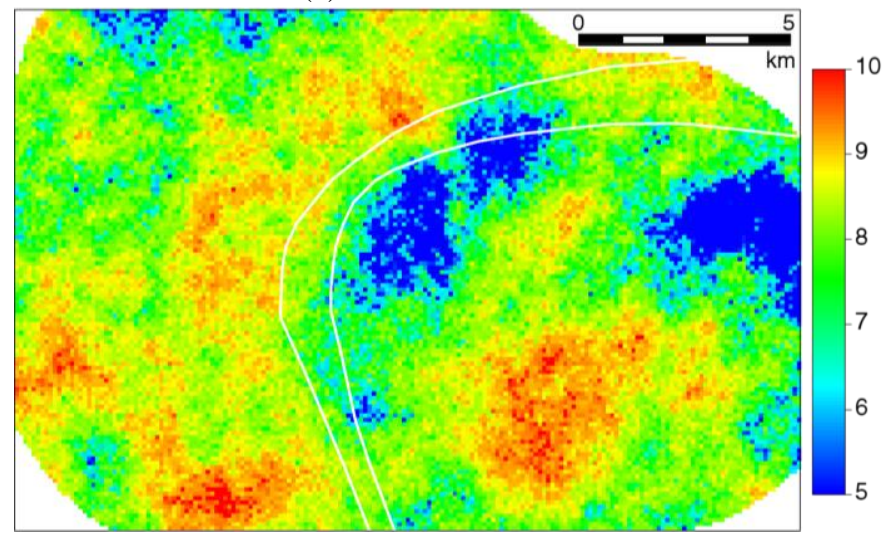

(b)

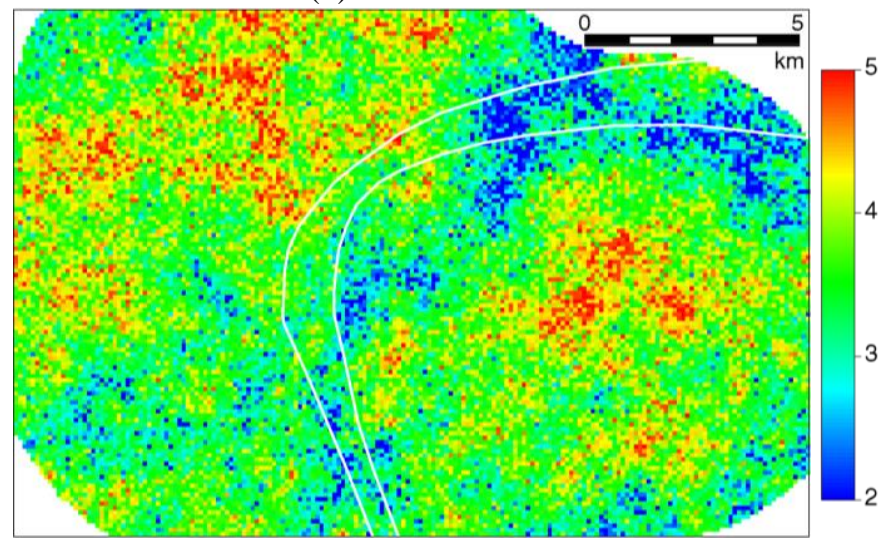

(c)

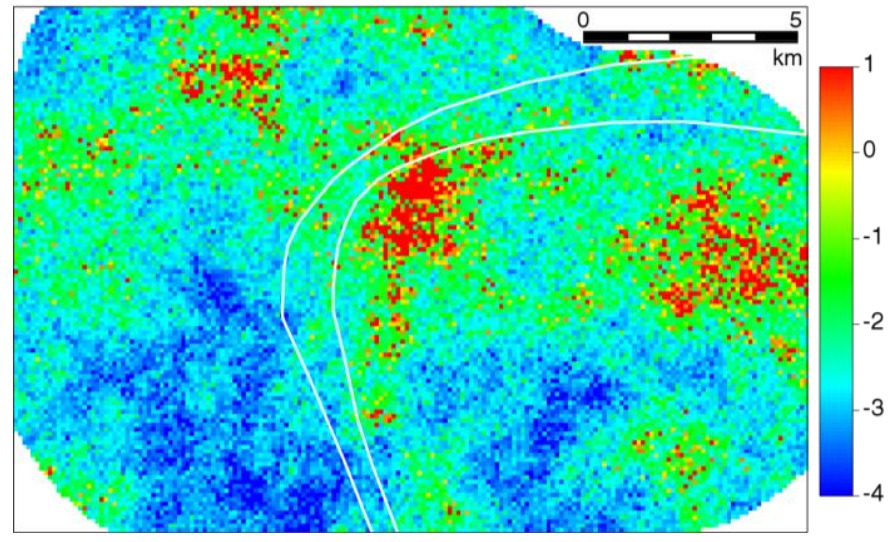

Fig. 5 Logratio maps, with the white curves marking the Ganges River margins: (a) balance 1; (b) balance 2; and (c) pseudologit for the sum of arsenic and iron concentrations.

Figs. 6 and 7 show the results for three realizations, this time properly selected to allow an appreciation of the degree of uncertainty in the results. These are conditional realizations, so they honor the values at all 95 wells (Figs. 1a and 1c) and have the same style of spatial fluctuation to the degree that such fluctuation can be captured by the semivariograms and crosssemivariograms in Fig. 4. The realizations are obtained by repeating node by node the same type 
of calculations in Eqs. 16-22, starting with the nodal values displayed in Fig. 5 and continuing with the remainder 99 realizations per variable. The fourth map in Figs. 6 and 7 is a filtered map of spatial fluctuation, maps that still honor the data but not the semivariograms and crosssemivariograms anymore. For each attribute, the realizations and the filtered map cover both realms of underlying and general style of fluctuation. Most likely, none of the realizations is the exact depiction of the underlying map, but collectively should help the reader to figure out the values that the attributes can take at those locations not considered in a sample of only 95 observations per attribute in an area of roughly $210 \mathrm{~km}^{2}$. The filtered map is an average map of all realizations, thus summarizing in one map all possibilities. The filtered version, while unique, is biased, because it provides a false rendition of the degree of complexity in the geographical variations of the attribute. Conceptually, a filtered map is the same map that would be obtained by (co)kriging the data instead of generating the (co)simulations. In that sense, stochastic simulation is a superior tool to kriging because it allows portraying both the actual fluctuations plus the map resulting from removing the high frequency components. Figs. $6 \mathrm{~d}$ and $7 \mathrm{~d}$ are simply a map of the compositional mean node by node, which are minimum mean square error estimates for the concentrations at those nodes (Remy et al. 2009). 
(a)

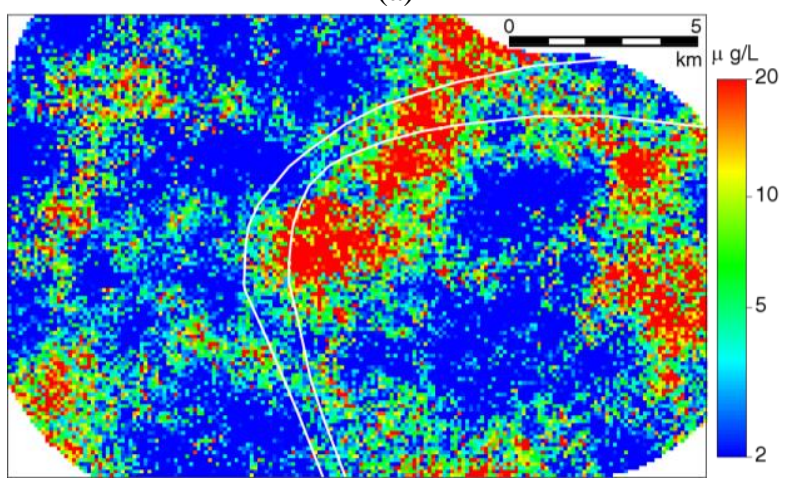

(c)

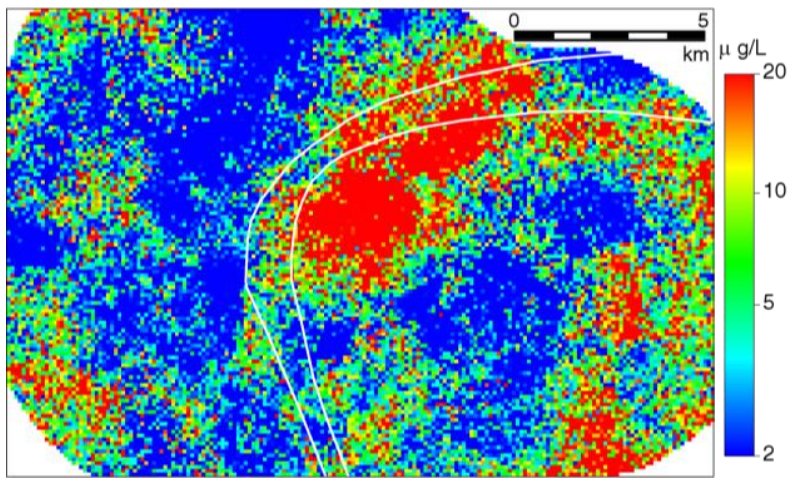

(b)

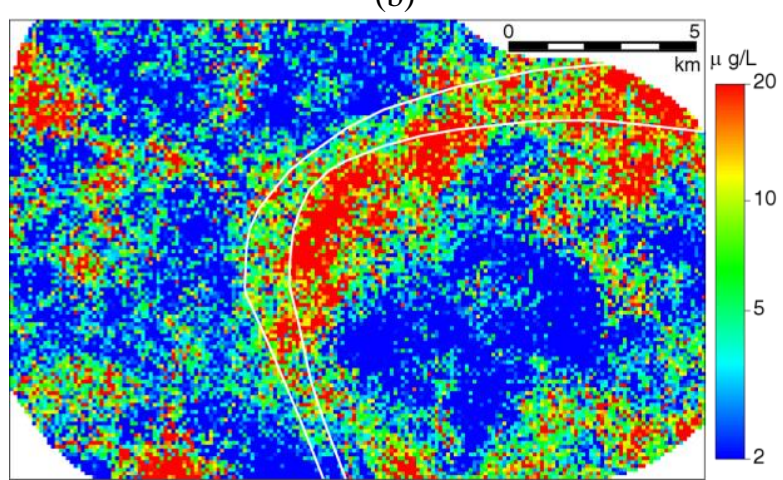

(d)

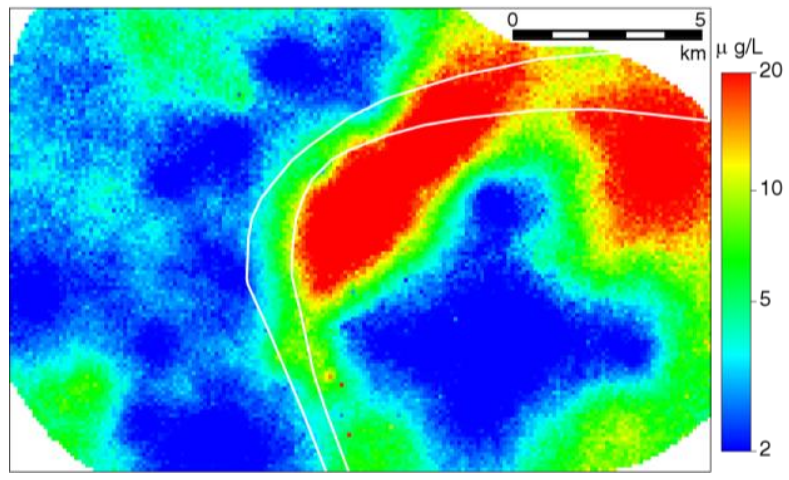

Fig. 6 Arsenic maps, with the white lines displaying the margins of the Ganges River: (a) realization with the $5^{\text {th }}$ lowest average concentration $(3.84 \mu \mathrm{g} / \mathrm{L})$; (b) realization with median concentration $(4.72 \mu \mathrm{g} / \mathrm{L})$; (c) realization with the $5^{\text {th }}$ largest average concentration $(5.47 \mu \mathrm{g} / \mathrm{L})$; (d) filtered map of concentration showing the general spatial trend. 
(a)

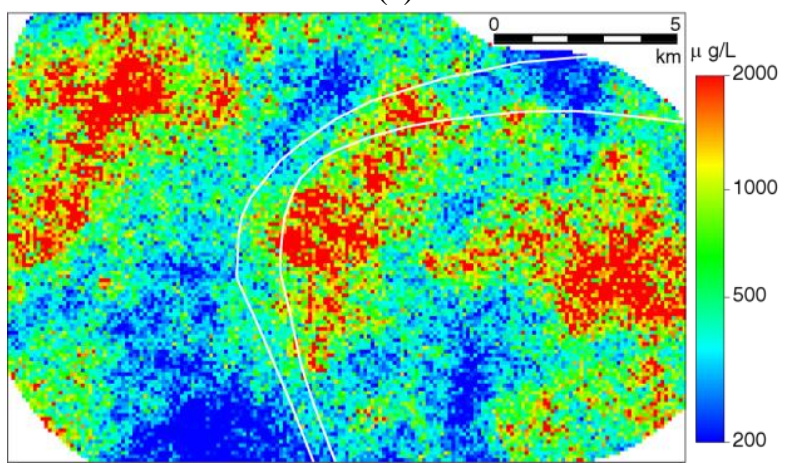

(c)

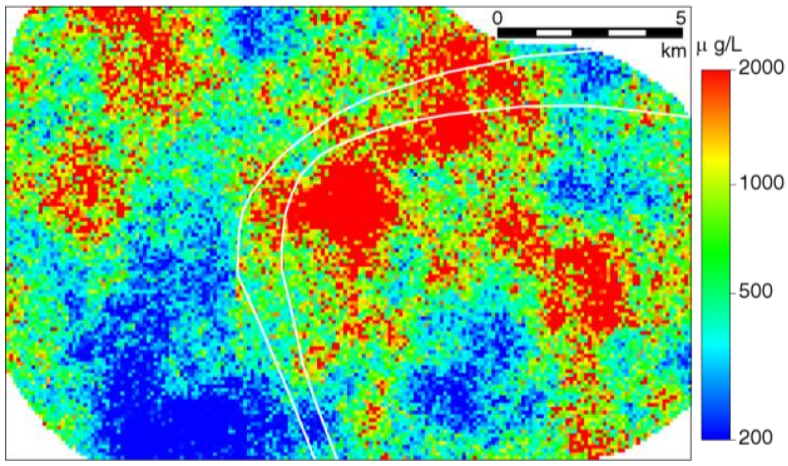

(b)

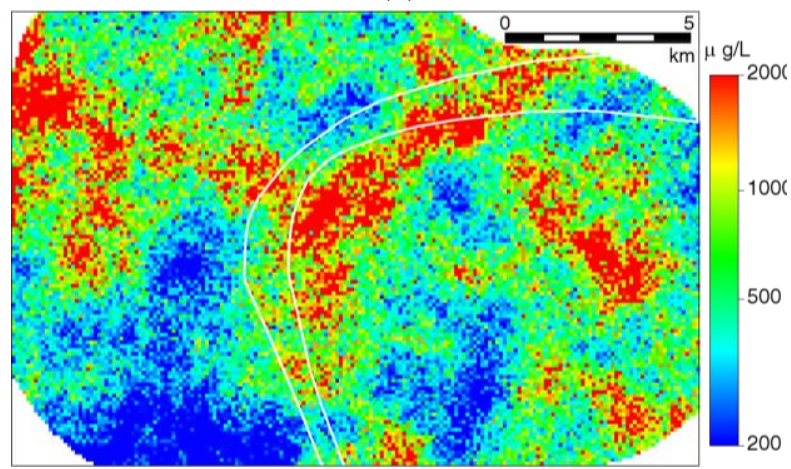

(d)

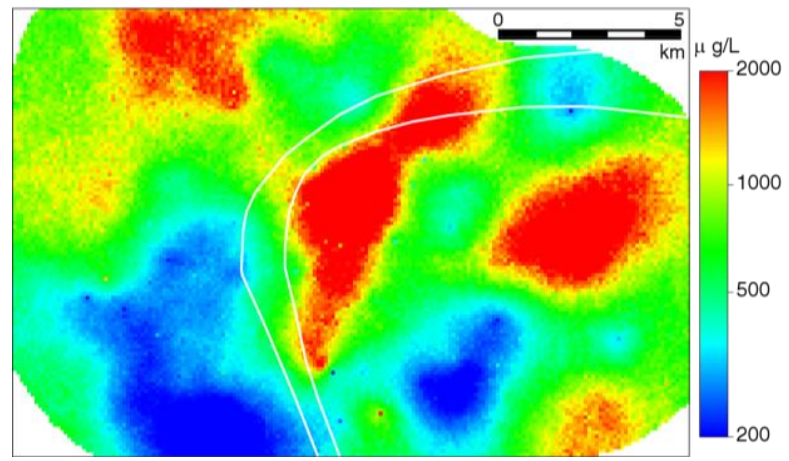

Fig. 7 Iron maps, with the white curves showing the Ganges River margins. Maps $(a-c)$ are for the corresponding realization in Figs. $6 a-6 c$, which have different ranks in terms of the percentiles for the average concentrations. (d) is the filtered map for iron concentration.

Map comparisons do not necessarily have to be done among a few realizations and done visually. The same probability distributions for every node that were used to calculate nodal means displayed as filtered maps can be used for other purposes, such as counting the proportion of values per node below or above certain thresholds. So, for example, if at node $\mathbf{s}_{i}$ the concentration of $\mathrm{Fe}\left(z_{1}\left(\mathbf{s}_{i}\right)\right)$ is higher than $800 \mu \mathrm{g} / \mathrm{L}$ for $32 \%$ of the values at the node, then we can estimate $\operatorname{Prob}\left[z_{1}\left(\mathbf{s}_{i}\right)>800\right]=0.32$, estimation that can be easily done and without resorting to any mathematical assumptions. Nothing prevents from expanding the comparison to more than one concentration by applying the same Eq. 1 behind sequential Gaussian simulation. For example, it is possible to calculate the joint probability that $A: F e>800$ and $B: A s>10$. Fig. 8 displays the results for the univariate and multivariate probabilities after carrying out the calculations for all nodes. Why $800 \mu \mathrm{g} / \mathrm{L}$ and $10 \mu \mathrm{g} / \mathrm{L}$ ? Because in this case the interest was to show the areas in which both elements were high. The value of $10 \mu \mathrm{g} / \mathrm{L}$ for As was taken directly from the critical value established by WHO. As for the $800 \mu \mathrm{g} / \mathrm{L}$ for $\mathrm{Fe}$, it was a value in the moderately high range of observed values (Fig. 2b). Taking another moderately high value, the results would have been different, but not by much. 
(a)

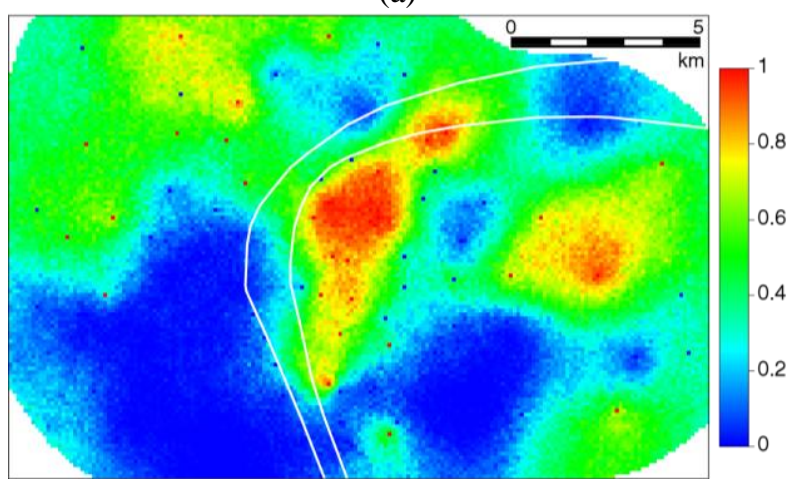

(b)

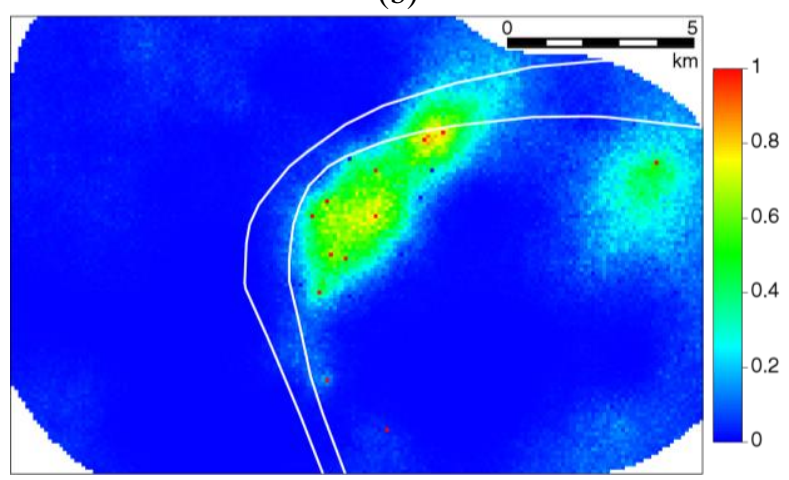

Fig. 8 Probability maps, with the white curves marking the margins of the Ganges River: (a) probability that the iron concentration is higher than $800 \mu \mathrm{g} / \mathrm{L}$; (b) probability that the iron concentration is higher than $800 \mu \mathrm{g} / \mathrm{L}$ and at the same time that of arsenic is higher than $10 \mu \mathrm{g} / \mathrm{L}$.

\section{Discussion}

According to Fig. 7, iron concentration in the groundwater of the study area is above $300 \mu \mathrm{g} / \mathrm{L}$ in most of the study area except primarily towards the southwest. Varanasi is on the concave side (erosional part) of a long meander (Fig. 1). The high arsenic concentrations should be expected on the convex side (depositional part) of the Ganges River (Fig. 6), higher in organic material (McArthur et al. 2001). Fig 8b indicates that simultaneous occurrence of high values for both iron and arsenic is restricted to two anomalies on the right margin of the river, where $\mathrm{Fe}$ oxyhydroxide coated sediment grains have been reported preferentially entrapped in more recent Holocene alluvial argillaceous sediments in entrenched channels and flood plains (Raju 2012). High concentrations of iron in north Varanasi are not associated with high concentrations of arsenic, most likely because of scarcer availability of organic matter. The sources of arsenic, iron and organic material are all natural, not of anthropogenic origin.

Varanasi is one of the oldest continuously occupied cities in the world that started and grew for millennia in the left banks of the Ganges River (Khan et al. 1988; Kayastha and Mohan 2000). Despite lack of technology only recently available, it looks like the ancient residents of Varanasi always knew that there was something unhealthy in the groundwater at the other side of the river that did not invite them to expand the city toward the east. Today, with the urban development at places like Ramnagar, Bhojpur, Kodpur, Kateswar, Domri, Madhiya, Bahadurpur, Sultanipur and Domanpati the populations at those communities are the ones that have the highest risks of developing health problems should they consume groundwater from local wells because of levels of As concentration above the $10 \mathrm{ppb}$ - roughly equal to $10 \mu \mathrm{g} / \mathrm{L}-$ established as the highest safe limit by WHO. 


\section{Conclusions}

Combined use of compositional data analysis and geostatistics allows to adequately preparing maps of continuous variations of hydrochemical attributes only partially known at the few locations where specimens have been taken for analysis. Their combined application provides for: (a) preparing realization maps honoring the data and the style of fluctuation-spatial correlation-implicit in the same data; (b) displaying one filtered map per attribute of interest showing only the low frequency fluctuations; and (c) reporting joint fluctuation of two of more attributes with their associated uncertainty.

Application of the methodology to reported values for 11 ions at 95 water wells in an area of about $210 \mathrm{~km}^{2}$ indicates that groundwater concentrations of arsenic at the city of Varanasi are significantly below the $10 \mathrm{ppb}$ recommended by the WHO. In contrast, a crescent of about 50 $\mathrm{km}^{2}$ underneath the Ganges and along the depositional side of the river meander east of Varanasi has levels of arsenic of natural origin in the groundwater that are above the maximum level recommended by WHO. Hence, public health authorities should prevent the consumption of groundwater from wells in all areas with high arsenic levels.

The mathematics in the methodology is completely general, not depending on the geochemical nature of the attributes. Hence, the study here can be used as a guide for the hydrochemical mapping of elements and ions in other places.

\section{Acknowledgments}

This paper completed a mandatory internal review by the U.S. Geological Survey (USGS) before final submission to the journal (http://pubs.usgs.gov/circ/1367/). We wish to thank Tanya Gallegos (USGS) and Josep Martín-Fernández (University of Girona) for suggestions that helped improving the manuscript.

SR/S4/ES-160/2005has been supported by the Department of Science and Technology (DST), New Delhi, under research project "SERC” (SR/S4/ES-160/2005) during 2006-2008.

J.J. Egozcue and V. Pawlowsky-Glahn have been supported by the Spanish Ministry of Education and Science under projects 'CODA-RETOS' (Ref. MTM2015-65016-C2-1-R MINECO/FEDER.UE) and 'COSDA' (Ref. 2014SGR551); and by the Agència de Gestió d'Ajuts Universitaris i de Recerca of the Generalitat de Catalunya. 


\section{References}

Acharyya SK (2005) Arsenic levels in groundwater from Quaternary alluvium in Ganga plain and the Bengal Basin, Indian Subcontinent: Insights into influence of stratigraphy. Gondwana Research 8(1):55-66

Aitchison J (2003) The statistical analysis of compositional data. The Blackburn Press, Caldwell, $\mathrm{NJ}$, reprint of 1986 edition plus 19 pages of new text, $435 \mathrm{pp}$

Aitchison J, Egozcue JJ (2005) Compositional data analysis: where are we and where should we be heading? Mathematical Geology 37(7):829-850

Ball JW, Nordstrom DK (1992) User's manual for WATEQ4F with revised thermodynamic database and test cases for calculating speciation of minor, trace and redox elements in natural waters. U.S. Geological Survey Open File Report 91-183, 189 pp

British Geological Survey (BGS) (2001) Arsenic contamination of groundwater in Bangladesh. Technical report, BGS, Department of Public Health Engineering (Bangladesh), Report WC/00/019, 630 pp, http://www.bgs.ac.uk/arsenic/Bangladesh/

Caers J (2011) Modeling Uncertainty in the Earth Sciences. Wiley-Blackwell, Chichester, UK, $229 \mathrm{pp}$

Chakraborti D, Mukherjee SC, Pati S, Sengupta MK, Rahman MM, Chowdhury UK, Lodh D, Chanda CR, Chakraborti AK, Basu GK (2003) Arsenic groundwater contamination in Middle Ganga Plain, Bihar, India: A future danger? Environmental Health Perspectives 111(9): 1194-1201

Chandana M, Enmark G, Nordborg D, Sracek O, Nath B, Nickson RT, Herbert R, Jacks G, Mukherjee A, Ramanathan AL, Choudhury R, Bhattacharya P (2015) Hydrogeochemical controls on mobilization of arsenic in groundwater of a part of Brahmaputra River flood plain, India. Journal of Hydrology: Regional Studies, 4:154-171

Chauhan VS, Nickson RT, Chauhan D, Iyengar L, Sankararamakrishnan N (2009) Ground water geochemistry of Ballia district, Uttar Pradesh, India and mechanism of arsenic release. Chemosphere 75(1):83-91

Chilès JP, Delfiner P (2012) Geostatistics: Modeling spatial uncertainty. John Wiley \& Sons, Inc., Hoboken, NJ, second edition, 734 pp

Egozcue JJ (2009) Reply to "On the Harker variation diagrams;..." by J. A. Cortés. Mathematical Geosciences 41(7):829-834

Egozcue JJ, Pawlowsky-Glahn V (2005) Groups of parts and their balances in compositional data analysis. Mathematical Geology 37(7):795-828

Egozcue JJ, Pawlowsky-Glahn V (2006) Simplicial geometry for compositional data. In:

Buccianti A, Mateu-Figueras G, Pawlowsky-Glahn V, editors, Compositional data analysis in the geosciences: From theory to practice. Geological Society Special Publication No. 264, London, 145-159 
Egozcue JJ, Pawlowsky-Glahn V (2011) Basic concepts and procedures. In: Pawlowsky-Glahn V, Buccianti A, editors, Compositional data analysis: Theory and applications. John Wiley \& Sons, Chichester, UK, 12-28

Egozcue JJ, Pawlowsky-Glahn V, Mateu-Figueras G, Barceló-Vidal C (2003) Isometric logratio transformations for compositional data analysis. Mathematical Geology 35(3):279-300

Emery X (2004) Testing the correctness of the sequential algorithm for simulating Gaussian random fields. Stochastic Environmental Research and Risk Assessment 18(6):401-413

Greenacre M (2011) Measuring subcompositional incoherence. Mathematical Geosciences 43(6):681-693

Hogg RV, McKean J, Craig AT (2012) Introduction to mathematical statistics. Pearson Education Ltd., Harlow, UK, $7^{\text {th }}$ edition, 649 pp

Isaacs EH, Srivastava RM (1989) An introduction to applied geostatistics. Oxford University Press, New York, 561 pp

Kayastha SL, Mohan A (2000) Varanasi: An ancient city of continuity and culture. Proceedings of the National Symposium Milestones in Petrology at the end of the Millennium and Future Perspectives, Department of Geology, Banaras Hindu University, Varanasi, pp. 20-29

Khan AA, Nawami PC, Srivastava MC (1988) Geomorphological evolution of the area around Varanasi, UP with the aid of aerial photographs and LANDSAT imageries. Geological Survey of India Rec. 113: 31-39

Kumar M, Kumar P, Ramanathan AL, Bhattacharya P, Thunvik R, Singh UK, Tsujimura M, Sracek O (2010) Arsenic enrichment in groundwater in the middle Gangetic Plain of Ghazipur District in Uttar Pradesh, India. Journal of Geochemical Exploration 105(3):83-94

Kumar M, Rahman MM, Ramanathan AL, Naidu R (2016) Arsenic and other elements in drinking water and dietary components from the middle Gangetic plain of Bihar, India: Health risk index. Science of Total Environment 539:125-134

McArthur JM, Ravenscroft P, Safiulla S, Thirlwall MF (2001) Arsenic in groundwater: testing pollution mechanism for sedimentary aquifers in Bangladesh. Water Resources Research 37(1):109-117

Meyzonnat G, Larocque M, Barbecot F, Pinti DL, Gagné S (2016) The potential of major ion chemistry to assess groundwater vulnerability of a regional aquifer in southern Quebec (Canada). Environmental Earth Sciences 75(1): article 68, 12 pp

Olea RA (2006) A six-step practical approach to semivariogram modeling. Stochastic Environmental Research and Risk Assessment 39(5):453-467

Olea, RA (2009) A Practical Primer on Geostatistics: U.S. Geological Survey, Open-File Report 2009-1103, 346 pp, http://pubs.usgs.gov/of/2009/1103 
Palarea-Albaladejo J, Martín-Fernández JA (2015) zCompositions-R package for multivariate imputation of left-censored data under a compositional approach. Chemometrics and Intelligent Laboratory Systems, 143:85-96

Pawlowsky-Glahn V, Egozcue JJ (2001) Geometric approach to statistical analysis on the simplex. Stochastic Environmental Research and Risk Assessment 15(5):384-398

Pawlowsky-Glahn V, Egozcue JJ (2016) Spatial analysis of compositional data: A historical review. Journal of Geochemical Exploration 164:28-32

Pawlowsky-Glahn V, Egozcue JJ, Lovell D (2015a) Tools for compositional data with a total. Statistical Modelling 15(2):175-190

Pawlowsky-Glahn V, Egozcue JJ, Olea RA, Pardo-Igúzquiza E (2015b) Cokriging of compositional balances including a dimension reduction and retrieval of original units. Journal of the Southern African Institute of Mining and Metallurgy 115(1):59-72

Pawlowsky-Glahn V, Egozcue JJ, Tolosana-Delgado R (2015c) Modeling and analysis of compositional data. John Wiley \& Sons Ltd, Chichester, UK, 247 pp

Pyrcz MJ, Deutsch CV (2014) Geostatistical reservoir modeling. New York, Oxford University Press, second edition, $433 \mathrm{pp}$

Raju, NJ (2012) Arsenic exposure through groundwater in the middle Ganga plain in the Varanasi environs, India: A future threat. Journal of the Geological Society of India 79:302-314

Remy N, Boucher A, Wu J (2009) Applied geostatistics with SGeMS—a user's guide. Cambridge University Press, Cambridge, UK, 264 pp

Rice EW, Baird RB, Eaton AD, Clesceri LS, editors (2012) Standard methods for the examination of water and wastewater. American Public Health Association, American Water Works Association, Water Environment Federation, Washington, DC, https://www.standardmethods.org/

Saha D, Shukla RR (2013) Genesis of arsenic rich groundwater and the search for alternative safe aquifers in the Gangetic plain, India. Water Environmental Research 85(12):2254-2264

Sha ZUH, Ahmad Z (2015) Hydrochemical mapping of the Upper Thal Doab (Pakistan) using the geographical information system. Environmental Earth Sciences 74(3):2757-2773

Shah BA (2010) Arsenic contaminated groundwater in Holocene sediments form part of middle Ganga plain, Uttar Pradesh, India. Current Science 98(10):1359-1365

Shukla UK, Raju NJ (2008) Migration of the Ganga River and its implications on hydrogeological potential of Varanasi area, U.P., India. Journal of Earth System Science 117(4):489-498

Singh IB (2004) Late Quaternary history of the Gangetic plain. Journal of the Geological Society of India 64:431-454 
Singh M, Singh IB, Muller G (2007) Sediment characteristics and transportation dynamics of the Ganga River. Geomorphology 86(1-2):144-175

Singh S, Raju NJ, Gossel W, Wycisk P (2016) Assessment of pollution potential of leachate from the municipal solid waste disposal site and its impact on groundwater quality, Varanasi environs, India. Arabian Journal of Geosciences 9(2): article 131, 12 pp

Srivastava P, Singh IB, Sharma M, Singhvi AK (2003) Luminescence chronometry and Late Quaternary geomorphic history of the Ganga Plain, India. Paleaogeography, Paleaoclimatology, Paleaoecology 197(1-2):15-41

Srivastava S, Sharma YK (2013) Arsenic occurrence and accumulation in soil and water of eastern districts of Uttar Pradesh, India. Environmental Monitoring and Assessment 185(6):4995-5002

Tandon SK, Gibling MR, Sinha R, Singh V, Ghazanfari P, Dasgupta A, Jain M, Jain V (2006) Alluvial valleys of the Ganga Plains, India: Timing and causes of incision. In: Dalrymple RW, Lickie DA, Tillman RW, editors, Incised valleys in time and space. Society for Sedimentary Geology (SEPM) Special Publications 85, Tulsa, OK, 15-35

Verly G (1993) Sequential Gaussian cosimulation: A simulation method integrating several types of information. In: Soares, A, editor, Geostatistics Troia'92. Kluwer Academic Publishers, Dordrecht, The Netherlands, vol. 1:543-552

Webster R, Oliver MA (2015) Basic steps in geostatistics: The variogram and kriging. Springer, Heidelberg, $100 \mathrm{pp}$

World Health Organization (WHO) (2011) Arsenic in drinking water, 16 pp, http://www.who.int/water_sanitation_health/dwq/chemicals/arsenic.pdf 


\section{Appendix}

Table A1. Results of laboratory analyses for 11 ions. WT stands for water table, DW for dug well, HTW for hand tube well, DBW deep borewell

\begin{tabular}{|c|c|c|c|c|c|c|c|c|c|c|c|c|c|c|}
\hline No. & Location & Source & $\begin{array}{l}\text { WT } \\
\mathrm{m}\end{array}$ & $\begin{array}{l}\mathrm{Fe} \\
\mu \mathrm{g} / \mathrm{L}\end{array}$ & $\begin{array}{l}\text { As } \\
\mu \mathrm{g} / \mathrm{L}\end{array}$ & $\begin{array}{l}\mathrm{Ca} \\
\mathrm{mg} / \mathrm{L}\end{array}$ & $\begin{array}{l}\mathrm{Mg} \\
\mathrm{mg} / \mathrm{L}\end{array}$ & $\begin{array}{l}\mathrm{Na} \\
\mathrm{mg} / \mathrm{L}\end{array}$ & $\begin{array}{l}\mathrm{K} \\
\mathrm{mg} / \mathrm{L}\end{array}$ & $\begin{array}{l}\mathrm{HCO}_{3} \\
\mathrm{mg} / \mathrm{L}\end{array}$ & $\begin{array}{l}\mathrm{SO}_{4} \\
\mathrm{mg} / \mathrm{L}\end{array}$ & $\begin{array}{l}\mathrm{Cl} \\
\mathrm{mg} / \mathrm{L}\end{array}$ & $\begin{array}{l}\mathrm{NO}_{3} \\
\mathrm{mg} / \mathrm{L}\end{array}$ & $\begin{array}{l}\mathrm{F} \\
\mathrm{mg} / \mathrm{L}\end{array}$ \\
\hline 1 & Malabia & HTW & -- & 285 & 2.3 & 62 & 31.3 & 13.9 & 3.6 & 334 & 10 & 35 & 7.3 & 0.89 \\
\hline 2 & Hyd. Gate-BHU & HTW & -- & 209 & 1.3 & 76 & 18.9 & 131 & 1.8 & 320 & 20 & 48 & 9.1 & 0.67 \\
\hline 3 & Agri.farm-BHU & HTW & -- & 230 & 2.8 & 16 & 58 & 19.5 & 2.6 & 286 & 30 & 26 & 6 & 0.75 \\
\hline 4 & Chittupur & HTW & -- & 415 & 1.9 & 100 & 60.8 & 47 & 2.8 & 318 & 121 & 120 & 1.1 & 0.48 \\
\hline 5 & Madarwa & DW & 14.5 & 336 & 2.2 & 46 & 40.2 & 17 & 4.4 & 322 & 5 & 46 & 5.7 & 0.59 \\
\hline 6 & Jagainpur & DW & 20 & 174 & 2.1 & 82 & 14 & 37.7 & 3.2 & 318 & 15 & 63 & 6.6 & 0.55 \\
\hline 7 & Samneghat & HTW & -- & 409 & 9 & 42 & 41.9 & 15.1 & 2.9 & 268 & 12 & 39 & 7.5 & 0.39 \\
\hline 8 & Karaundi & DW & 11.6 & 321 & 1.8 & 70 & 127 & 111 & 2.7 & 510 & 180 & 198 & 0.82 & 0.82 \\
\hline 9 & IMS (BHU) & HTW & -- & 319 & 2.5 & 20 & 65 & 29.9 & 2.7 & 286 & 70 & 40 & 6.8 & 0.86 \\
\hline 10 & Bhagavanpur & DW & 8.9 & 282 & 3 & 24 & 59 & 52.7 & 3.8 & 364 & 30 & 55 & 4.5 & 0.65 \\
\hline 11 & Nagwa Chungi & HTW & 10 & 414 & 2.7 & 20 & 56.1 & 33.8 & 3.4 & 318 & 15 & 53 & 6.8 & 0.95 \\
\hline 12 & Lanka & DW & 7.2 & 346 & 23 & 22 & 105 & 86 & 2.4 & 382 & 150 & 128 & 1.2 & 0.88 \\
\hline 13 & Sunderpur & HTW & -- & 175 & 1.9 & 36 & 65.2 & 64.8 & 2.3 & 404 & 10 & 93 & 1.3 & 0.77 \\
\hline 14 & Saketnagar & HTW & -- & 281 & 2.4 & 46 & 62.7 & 33 & 3 & 342 & 60 & 74 & 1.8 & 0.85 \\
\hline 15 & Nagwa & DW & -- & 424 & 2.5 & 52 & 48.6 & 41.4 & 6.2 & 302 & 5 & 50 & 3.1 & 0.56 \\
\hline 16 & Bhulanpur & DW & -- & 383 & 1.1 & 52 & 50.9 & 20 & 3 & 350 & 10 & 35 & 35 & 0.8 \\
\hline 17 & Bikharipur & DW & 7.6 & 207 & 3.2 & 58 & 45.6 & 58 & 2.3 & 360 & 30 & 98 & 6.8 & 0.63 \\
\hline 18 & Sarainand. & DW & 11.8 & 255 & 2.9 & 18 & 48.5 & 68 & 3 & 304 & 30 & 80 & 3.4 & 0.51 \\
\hline 19 & Ravindrap. & HTW & -- & 282 & 2.1 & 80 & 22.4 & 25.4 & 2.6 & 264 & 30 & 60 & 2.5 & 0.49 \\
\hline 20 & Assighat & DW & 2.4 & 255 & 1.5 & 48 & 56.6 & 74.9 & 4.3 & 370 & 60 & 95 & 2 & 0.67 \\
\hline 21 & Karkarmitha & DW & -- & 1262 & 1.8 & 62 & 49.8 & 76.5 & 4.2 & 145 & 100 & 149 & 90.4 & 0.46 \\
\hline 22 & Kheiriya & HTW & -- & 214 & 2.3 & 10 & 119 & 144 & 2.7 & 524 & 120 & 163 & 1.5 & 0.85 \\
\hline 23 & Shivala & HTW & -- & 401 & 2.3 & 40 & 41.3 & 52.5 & 40 & 304 & 75 & 65 & 2.7 & 0.73 \\
\hline 24 & Belupur & HTW & -- & 286 & 1.9 & 36 & 69.3 & 108 & 28 & 382 & 120 & 138 & 1.2 & 0.66 \\
\hline 25 & Sonarpura & HTW & -- & 306 & 2.9 & 16 & 58.4 & 73.6 & 53.3 & 410 & 50 & 93 & 3.7 & 0.76 \\
\hline 26 & Sivadaspur & DW & 11.2 & 870 & 2.2 & 57 & 43 & 64.7 & 7.9 & 173 & 30 & 97 & 63.6 & 0.53 \\
\hline 27 & Koluwaa & HTW & -- & 356 & 3.3 & 10 & 49.8 & 130 & 5.1 & 366 & 50 & 99 & 2.2 & 0.64 \\
\hline 28 & Kamachha & DW & 5.3 & 441 & 3.5 & 40 & 51.5 & 94 & 28.4 & 386 & 90 & 87 & 3.2 & 0.73 \\
\hline 29 & Chandpura & HTW & -- & 730 & 2.4 & 52 & 33 & 49.5 & 3 & 310 & 20 & 40 & 62.4 & 0.69 \\
\hline 30 & Manduadi & DW & 9.8 & 980 & 2.2 & 59 & 39.2 & 80.4 & 4 & 356 & 20 & 79 & 76 & 0.31 \\
\hline 31 & Gurubagh & HTW & 12 & 660 & 1.8 & 49 & 70.5 & 107 & 6.6 & 260 & 100 & 169 & 92 & 0.6 \\
\hline 32 & Jangambadi & DW & 1.4 & 940 & 1.9 & 37 & 50.3 & 64.5 & 33 & 315 & 100 & 72 & 11 & 1.12 \\
\hline 33 & Koharpur & DW & -- & 830 & 2.1 & 53 & 65 & 40 & 3 & 332 & 40 & 109 & 55.1 & 0.54 \\
\hline 34 & Cant.Railway St & HTW & 7.4 & 980 & 2 & 55 & 32 & 100 & 2.8 & 412 & 40 & 49 & 66.7 & 1.34 \\
\hline 35 & Sonia Pokhara & DW & 4.3 & 890 & 1 & 50 & 32.7 & 77.6 & 5.7 & 235 & 90 & 56 & 36.6 & 0.94 \\
\hline 36 & Central Prison & DW & -- & 800 & 2.7 & 56 & 49.1 & 75.2 & 4.5 & 310 & 70 & 109 & 35 & 0.36 \\
\hline 37 & Nadeshwar & DW & -- & 800 & 2.9 & 76 & 20 & 129 & 8.1 & 430 & 60 & 12 & 20.4 & 0.34 \\
\hline 38 & Rajanhia & DW & -- & 1480 & 3 & 39 & 46.2 & 59.5 & 2.6 & 375 & 30 & 39 & 48.7 & 0.98 \\
\hline 39 & Sanskrat Univ. & DW & 8 & 1060 & 2.5 & 80 & 8.2 & 39.6 & 3.6 & 310 & 10 & 35 & 9.6 & 0.55 \\
\hline 40 & City Railway St. & HTW & 9.8 & 730 & 2 & 100 & 92.5 & 200 & 6.5 & 320 & 120 & 397 & 106 & 0.63 \\
\hline 41 & Rasulgarh & DW & 17.2 & 860 & 1.9 & 50 & 10.8 & 41.2 & 2.8 & 288 & 20 & 40 & 47.7 & 0.51 \\
\hline 42 & Kapiladara & DW & -- & 670 & 1.7 & 46 & 41.8 & 90.2 & 3 & 395 & 20 & 107 & 23.1 & 0.82 \\
\hline 43 & Kotwara & DW & 17.3 & 500 & 3.5 & 69 & 26.1 & 70.3 & 3.5 & 385 & 10 & 51 & 67.1 & 0.46 \\
\hline 44 & Rajghat & DW & 24.1 & 430 & 3.2 & 79 & 36.6 & 92 & 75 & 340 & 100 & 175 & 92 & 0.45 \\
\hline 45 & Bahadurpur & HTW & 3.1 & 5319 & 80 & 183 & 15.3 & 32 & 2.1 & 364 & 100 & 109 & 2.7 & 1.2 \\
\hline 46 & Domari & HTW & -- & 438 & 3 & 105 & 12.1 & 25.8 & 2.4 & 386 & 2.5 & 37 & 2.1 & 0.8 \\
\hline 47 & Ratanpur & HTW & -- & 4065 & 23 & 103 & 22.5 & 42.1 & 4.1 & 447 & 2.5 & 45 & 2.5 & 0.9 \\
\hline 48 & Madhiya & HTW & -- & 362 & 76 & 107 & 45.8 & 31.6 & 2.1 & 405 & 10 & 115 & 3.1 & 1.1 \\
\hline 49 & Semra & HTW & 3.7 & 1382 & 24 & 145 & 29.6 & 26.8 & 1.1 & 343 & 100 & 97 & 2.4 & 1 \\
\hline 50 & Bhojpur & HTW & -- & 6866 & 45 & 113 & 30.5 & 24.5 & 1.7 & 447 & 10 & 59 & 2.4 & 0.5 \\
\hline 51 & Jalilpur & HTW & -- & 421 & 11 & 73 & 20.8 & 23.2 & 2.3 & 295 & 2.5 & 47 & 5.6 & 0.7 \\
\hline 52 & Kateswar & HTW & -- & 1436 & 31 & 101 & 31.9 & 20.4 & 0.8 & 426 & 2.5 & 43 & 5 & 0.9 \\
\hline 53 & Bhakhara & HTW & -- & 353 & 13 & 71 & 3.1 & 45.2 & 1.7 & 288 & 2.5 & 53 & 5.4 & 1.1 \\
\hline 54 & Nibupur & HTW & -- & 323 & 3.8 & 37 & 86.8 & 150 & 7.3 & 720 & 2.5 & 103 & 11.9 & 0.8 \\
\hline
\end{tabular}




\begin{tabular}{|c|c|c|c|c|c|c|c|c|c|c|c|c|c|c|}
\hline 55 & Kodupur & HTW & -- & 365 & 14 & 107 & 34.2 & 97.3 & 2.2 & 589 & 5 & 79 & 3.8 & 1.2 \\
\hline 56 & Wajidpur & HTW & -- & 2464 & 3 & 85 & 0.4 & 73.1 & 2.1 & 312 & 2.5 & 61 & 4.1 & 0.9 \\
\hline 57 & Nathupur & HTW & -- & 526 & 1.9 & 79 & 21.3 & 34.9 & 0.7 & 345 & 2.5 & 57 & 5.8 & 0.7 \\
\hline 58 & Nathupur & HTW & -- & 727 & 1.2 & 75 & 8.4 & 32 & 0.7 & 232 & 2.5 & 41 & 3.6 & 1.3 \\
\hline 59 & Kutulupur & HTW & -- & 3527 & 2.4 & 123 & 93.5 & 69.2 & 18.2 & 572 & 30 & 225 & 44.7 & 0.8 \\
\hline 60 & Sultanpur & DW & 3.5 & 492 & 2.8 & 75 & 35.6 & 123 & 1.2 & 378 & 10 & 157 & 16.1 & 1.2 \\
\hline 61 & Mannapur & DW & -- & 450 & 2.9 & 68 & 64 & 252 & 23.1 & 694 & 10 & 277 & 21.9 & 0.9 \\
\hline 62 & Kabirpur & HTW & -- & 835 & 1.6 & 25 & 44.6 & 235 & 1.6 & 682 & 20 & 111 & 11.2 & 0.7 \\
\hline 63 & Dariyapur & DW & -- & 355 & 1.1 & 59 & 47.3 & 102 & 2.5 & 537 & 10 & 85 & 10.4 & 0.45 \\
\hline 64 & Parawara & DW & -- & 329 & 1.8 & 81 & 46.5 & 114 & 9.8 & 502 & 5 & 163 & 6.2 & 0.5 \\
\hline 65 & Bhiti & HTW & -- & 320 & 3 & 73 & 25.6 & 83.2 & 0.7 & 325 & 100 & 79 & 6.24 & 0.6 \\
\hline 66 & Dahiya & DW & -- & 100 & 1.9 & 53 & 50.2 & 87.3 & 1.1 & 416 & 2.5 & 83 & 5.4 & 0.9 \\
\hline 67 & Tangara & DW & -- & 360 & 2.9 & 11 & 50.2 & 180 & 1.3 & 547 & 2.5 & 109 & 11.9 & 0.8 \\
\hline 68 & Rathupur & HTW & -- & 346 & 2.7 & 59 & 20.5 & 35.7 & 0.6 & 294 & 10 & 29 & 8.7 & 0.9 \\
\hline 69 & Pongalpur & HTW & -- & 400 & 9 & 97 & 13.5 & 281 & 1.5 & 568 & 45.4 & 262 & 22.4 & 0.7 \\
\hline 70 & Karaya & HTW & -- & 100 & 1.3 & 74 & 44.5 & 109 & 109.4 & 450 & 30.2 & 210 & 70 & 2 \\
\hline 71 & Ralhupur & HTW & 3.5 & 250 & 19 & 84 & 21.9 & 156 & 17 & 385 & 34 & 200 & 9.2 & 0.9 \\
\hline 72 & Tengara & DW & -- & 3390 & 10 & 82 & 68.8 & 192 & 1.9 & 628 & 60 & 220 & 13.2 & 1 \\
\hline 73 & Kataria & DW & -- & 170 & 1.4 & 60 & 39.4 & 123.5 & 4.2 & 386 & 64 & 120 & 3.5 & 1 \\
\hline 74 & Ekuni & DW & 4.2 & 520 & 2.9 & 30 & 41.3 & 288 & 6.8 & 650 & 53.1 & 240 & 1.5 & 2 \\
\hline 75 & Chakia & HTW & -- & 1000 & 6 & 98 & 17.1 & 139 & 2 & 293 & 208 & 98 & 9.7 & 0.4 \\
\hline 76 & Taranpur & DBW & -- & 500 & 6 & 82 & 22.6 & 76.3 & 2.5 & 326 & 16 & 118 & 3.2 & 0.5 \\
\hline 77 & Prasrampur & DBW & 3.9 & 300 & 1.3 & 70 & 34 & 48.2 & 2.8 & 311 & 25.6 & 82 & 5.5 & 1 \\
\hline 78 & Kamlapur & HTW & 2.7 & 350 & 1.8 & 62 & 20.7 & 124.4 & 2.7 & 418 & 64.5 & 80 & 67 & 2 \\
\hline 79 & Airi & DBW & -- & 100 & 1.5 & 82 & 32.8 & 96.9 & 4.4 & 433 & 30.3 & 98 & 6 & 2 \\
\hline 80 & Bengali & DBW & 3.4 & 200 & 22 & 58 & 52.3 & 80.4 & 1.7 & 335 & 70.6 & 118 & 8.9 & 1 \\
\hline 81 & Bagheli Tola & DW & 4.1 & 6900 & 15 & 92 & 1.3 & 278 & 7.9 & 317 & 110 & 280 & 90 & 0.5 \\
\hline 82 & Parorwa & HTW & -- & 380 & 1.6 & 106 & 13.4 & 95 & 3.2 & 410 & 29.9 & 124 & 7 & 0.8 \\
\hline 83 & Khajurgaon & DBW & -- & 170 & 1.4 & 86 & 17.8 & 87 & 2.3 & 366 & 40 & 88 & 1.9 & 1 \\
\hline 84 & Kodpur & HTW & -- & 980 & 36 & 94 & 4.2 & 104.4 & 2.7 & 365 & 60 & 118 & 4.3 & 0.4 \\
\hline 85 & Katesar & DBW & 2.2 & 1200 & 21 & 110 & 1.8 & 27.2 & 2.2 & 220 & 23.9 & 95 & 4.7 & 0.2 \\
\hline 86 & Shahupuri Col. & DW & -- & 1600 & 1.5 & 236 & 31.72 & 125 & 2.9 & 319 & 19.2 & 494 & 1.9 & 0.7 \\
\hline 87 & Chandhasi & HTW & -- & 6000 & 6.6 & 138 & 19.3 & 200 & 4.9 & 518 & 90.2 & 207 & 62.6 & 2 \\
\hline 88 & Mughal Sarai & HTW & -- & 700 & 8 & 60 & 26.3 & 111.6 & 39 & 360 & 57.8 & 119 & 13.4 & 2 \\
\hline 89 & Semra & HTW & 6.2 & 6400 & 23 & 162 & 3.7 & 48.2 & 2.2 & 360 & 13 & 148 & 3 & 0.2 \\
\hline 90 & Domri & HTW & -- & 700 & 30 & 130 & 13 & 88.7 & 2.8 & 392 & 100.5 & 95 & 5.9 & 0.2 \\
\hline 91 & Bahadurpur & HTW & 4.9 & 4000 & 72 & 196 & 5 & 91.8 & 13 & 612 & 14 & 135 & 19 & 0.2 \\
\hline 92 & Dhulaipur & HTW & 5.6 & 700 & 1.5 & 190 & 35.3 & 175.1 & 5.7 & 657 & 89.9 & 247 & 1.3 & 0.7 \\
\hline 93 & Vyasnagar & DW & 3.6 & 1300 & 1.4 & 260 & 4.5 & 93.1 & 1.4 & 292 & 26.4 & 417 & 3.3 & 0.5 \\
\hline 94 & Domanpati & HTW & 2.9 & 900 & 70 & 139 & 20.9 & 135.8 & 9.8 & 571 & 24.2 & 123 & 21.3 & 0.2 \\
\hline 95 & Sultanipur & HTW & 4.1 & 200 & 48 & 82 & 26.8 & 68.4 & 4.6 & 340 & 29 & 102 & 11.9 & 0.7 \\
\hline
\end{tabular}

